\title{
Sedimentología y paleoambientes de la Formación La Laja (Cámbrico), Quebrada La Laja, Sierra Chica de Zonda, San Juan, Argentina
}

Fernando J. Gómez

Laboratorio de Análisis de Cuencas, Cátedra de Estratigrafía y Geología Histórica, Facultad de Ciencias Exáctas, Físicas y Naturales, Universidad Nacional de Córdoba Av. Vélez Sarsfield 1611, $2^{\circ}$ Piso Of. 7 X5016GCA Córdoba, Argentina-CONICET

Ricardo A. Astini

fgomez@efn.uncor.edu raastini@efn.uncor.edu

RESUMEN

La Formación La Laja es una unidad clave en el marco de las teorías existentes respecto a la Precordillera Argentina, considerada como un 'terrane' alóctono proveniente de Laurentia y ubicado actualmente en los Andes Centrales del sur. Esta unidad constituye (junto a La Formación Cerro Totora) la base de la plataforma carbonática Paleozoica Inferior. Es precisamente en estas unidades basales donde se encontraría registrada la historia de separación y deriva de este terrane exótico a Gondwana. La Formación La Laja es una unidad dominantemente calcárea que, a diferencia del resto de las que componen la sucesión cambro-ordovícica de la Precordillera, presenta intervalos con sedimentación mixta silicoclástica-carbonática. En el presente trabajo se realizó un detallado análisis de facies a través de los cinco miembros reconocidos dentro de esta formación en la sección de referencia aflorante en la quebrada La Laja (Sierra Chica de Zonda). Se reconocieron 19 microfacies principales agrupadas en 4 asociaciones de facies principales: 1) submareales relativamente profundas con influencia de tormentas e importante participación de sedimentos silicoclásticos finos, 2) submareales someras, 3) submareales someras mixtas, y 4) submareales a intermareales, ocasionalmente con desarrollo de ciclos de alta frecuencia, típicos de llanuras de mareas. No hay evidencias en esta sección de desarrollo de facies más profundas, correspondientes a ambiente de talud o cuenca marina profunda. En contraposición la unidad registra ambientes someros con algunos episodios de exposición subaérea. Calizas arenosas y areniscas calcáreas ricas en feldespatos pueden observarse en el Miembro El Estero. Depósitos submareales de aspecto cíclico, coronados por barras oolíticas pueden observarse en la base del Miembro Soldano. Intervalos de profundización por debajo del tren de oleaje de tormentas con abundante participación de material terrígeno (margas y calizas nodulares) se registran en los miembros Soldano y Juan Pobre, donde resaltan tempestitas con abundantes restos esqueletales y ricas en oolítas. Etapas de somerización y exposición subaérea se reconocen dentro de los miembros Rivadavia y Las Torres con desarrollo de facies de calizas bandeadas con abundantes niveles intraclásticos, superficies microkársticas y brechas de exposición. Cuerpos oolíticos con sets de estratificación cruzada bipolar, asignables a sistemas de barras oolíticas, son comunes en el tope del Miembro Las Torres. El pasaje a la Formación Zonda está indicado por una abrupta reorganización de los sistemas depositacionales y desarrollo de ciclos perimareales de escala métrica coronados por un término microbialítico. Distintos órdenes de ciclicidad superpuestos pueden reconocerse dentro de la Formación La Laja. La presencia de ciclos de mayor escala ('Grandes Ciclos') se infiere a partir de la alternancia de intervalos con abundante participación de silicoclásticos, a los que se sobreimponen ciclos de mayor frecuencia y escala métrica que reflejan una historia depositacional compleja donde interactúan factores ambientales y tectono-eustáticos.

Palabras claves: Calizas, Precordillera Argentina, Sierra Chica de Zonda, Quebrada La Laja, Formación La Laja, Cámbrico, Argentina

Revista Geológica de Chile, Vol. 33, No. 1, p. 19-46, 7 Figs., 1 tabla, Enero 2006. 


\begin{abstract}
Sedimentology and paleoenvironments of the La Laja Formation (Cambrian), Quebrada La Laja, Sierra Chica de Zonda, San Juan, Argentina. The La Laja Formation is a key unit regarding the hypothesis of the Argentine Precordillera as a Laurentia-derived allochtonous terrane in the south central Andes. Together with the Cerro Totora Formation it comprises the oldest unit exposed at the base of the Lower Paleozoic carbonate platform of the Precordillera. According to previous work these units record the rifting-drifting history of this terrane exotic to Gondwana. The La Laja Formation contrasts with the rest of the overlying units of the Cambro-Ordovician carbonate platform by being partly mixed carbonate-siliciclastic. A detailed facies analysis of the five recognized members in the reference section at Quebrada La Laja (Sierra Chica de Zonda, San Juan Province) allow the recognition of 19 microfacies grouped into four main environmentally significant associations: 1) a storm-influenced, deep subtidal environment with variable influx of fine siliciclastic sediments; 2) shallow subtidal, 3) mixed shallow subtidal and 4) shallow subtidal to intertidal occasionally with well developed high-frequency tidal flat cycles. No deeper basinal or slope facies were found. In contrast, the unit largely records shallow-marine facies with some evidence of subaerial exposure. Medium to coarse, calcareous, feldspar-rich sandstones and sandy limestones characterize the El Estero Member. The base of the Soldano Member shows profuse development of cyclicity with capping oolitic shoals. This member and the upper Juan Pobre Member contain deeper subtidal intervals, below the storm weather wave base, with high percentages of fine terrigenous material represented by shaly marls and nodular limestones. Skeletal-rich and oolite-rich storm beds are recorded within them. Relative shallowing to subaerial environments recorded within the Rivadavia and Las Torres members, with the development of ribbon limestones, intraclastic rudstones, microkarstic surfaces and exposure breccias. Herringbone cross-bedded oolite shoals are common at the top of the uppermost Las Torres Member. The transition into the overlying Zonda Formation is represented by an abrupt rearrangement of the depositional systems and development of meterscale microbial-rich peritidal cycles. Several orders of superposed cyclicity are recorded within the La Laja Formation. Larger-scale cycles ('Grand Cycles') are inferred from alternating members with important amounts of siliciclastics, whereas meter-scale cycles indicate higher frequency superposed mechanisms. Altogether these show a complex depositional history linking environmental and tectono-eustatic signatures.
\end{abstract}

Key words: Limestones, Argentinian Precordillera, Sierra Chica de Zonda, Quebrada La Laja, La Laja Formation, Cambrian, Argentina.

\title{
INTRODUCCIÓN
}

La Precordillera Argentina se destaca por presentar características tectosedimentarias notablemente diferentes de las demás sucesiones aflorantes a lo largo del margen occidental de Sudamérica. Esto ha generado diferentes modelos tendientes a comprender tales diferencias. Aunque algunos autores consideraron a la Precordillera como un terreno autóctono (González Bonorino y González Bonorino, 1991) o parautóctono con respecto al margen occidental de Gondwana (Baldis et al., 1989; Loske, 1993; Aceñolaza et al., 2002), numerosos autores se han inclinado por la hipótesis de aloctonía de la Precordillera, sobre la base de: afinidades estratigráficas (Bond et al., 1984; Astini et al., 1995 y 1996; Thomas y Astini, 1999, entre otros), paleomagnéticas (Rapalini y Astini, 1998), faunísticas (Vaccari, 1994; Benedetto, 2004 y referencias allí citadas) y geocronológicas (Thomas et al., 2004). Estas evidencias permiten restituir la posición original de este fragmento en el paleocontinente de Laurentia. A partir del acuerdo respecto de la aloctonía de la Precordillera (Dalziel et al., 1996; Ramos, 2004), resultan controvertidos los modelos propuestos sobre su transferencia, como así también el momento en que ocurrió el traslado y su acrección al margen occidental de Gondwana (véase Dalla Salda et al., 1992; Dalziel et al., 1994; Dalziel, 1997; Astini et al., 1995, 1996; Keller, 1999). De acuerdo con la hipótesis de aloctonía de Astini et al. (1995), la Precordillera constituiría una microplaca que, luego de un proceso inicial de 'rifting' desarrollado durante el Cámbrico inicial (Thomas y Astini, 1999), se separó del margen sudoriental de Laurentia y tras un periodo de deriva y aislamiento en el Océano lapetus, colisionó con el margen occidental de Gondwana en el Ordovícico Medio a Superior. De acuerdo con esta hipótesis, los estadíos iniciales de dicha historia estarían 
representados en las Formaciones Cerro Totora y La Laja (Astini et al., 1996), Cámbrico Inferior altoCámbrico Medio (Bordonaro, 1980, 1986 y 1999), que constituyen las unidades basales de la plataforma precordillerana. De lo antes dicho se hace evidente la importancia del estudio detallado de estas unidades, y las implicancias que un conocimiento acabado de las mismas tiene en la comprensión de la evolución temprana de la Precordillera Argentina y del margen proto-andino.

El principal objetivo de esta contribución es brindar un análisis estratigráfico de detalle de la Formación La Laja en la sección de referencia, con el fin de establecer con mayor precisión su interpretación paleoambiental e identificar patrones que permitan discutir su evolución. Esto permitirá en un futuro establecer correlaciones mas precisas con otras secciones aflorantes a lo largo de la Precordillera, permitiendo así documentar la distribución de los cinturones de facies dentro de la cuenca y de su evolución espacial y temporal.

\section{FORMACIÓN LA LAJA: ANTECEDENTES}

La Formación La Laja (Borrello, 1962), junto a las demás sucesiones carbonáticas cambroordovícicas, aflora casi ininterrumpidamente a lo largo de la Precordillera Oriental, tanto en la sierra de Villicúm, al norte, como en la sierra Chica de Zonda al sur (Fig. 1a). En ésta última, posee afloramientos continuos entre el río San Juan al norte y la Loma Redonda al sur, pudiendo incluirse
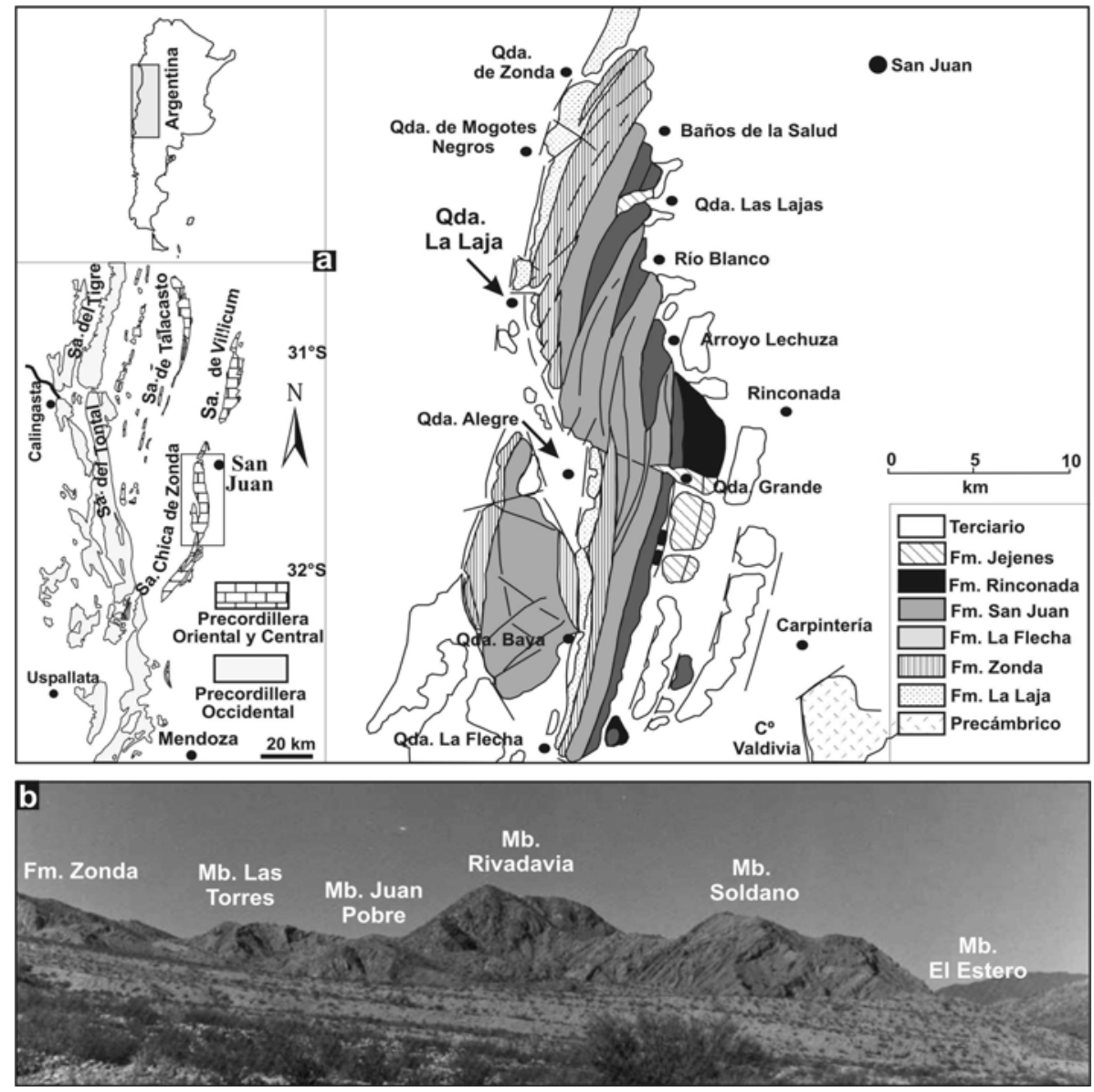

FIG. 1. (a)-extremo norte de la sierra Chica de Zonda, desde la quebrada La Flecha hasta la quebrada de Zonda y su ubicación dentro de la Precordillera Argentina (tomado de Baldis y Bordonaro 1984); (b)-vista panorámica de la Formación La Laja en la sección correspondiente a la quebrada La Laja. Fotografía tomada desde el Valle de Zonda (margen occidental de la sierra de Zonda) hacia el sudeste donde se ve la unidad manteando hacia el este. 
un afloramiento aislado en la región del río Acequión (Baldis y Bordonaro, 1984).

Borrello (1962) estableció como estratotipo de la Formación La Laja la sección aflorante en la quebrada de Zonda (Fig. 1a), sobre el trazado de la ruta nacional 20 , 'entre la hostería y el km 21', y descubrió el Cámbrico Inferior al pie del flanco sudoccidental de la sierra de Villicúm (Fig. 1a), estableciendo la zona de Olenellus (Borrello, 1963). Stelzner (1923-1924) y Kayser (1923) describieron inicialmente faunas de trilobites que fueron luego revisadas por Harrington y Leanza (1943). Estos autores determinaron la presencia del Cámbrico Medio. Poulsen (1958) reconoció la zona de Glossopleura, proporcionando el primer elemento diagnóstico para correlacionarla a nivel mundial. Posteriormente, se definieron en otras localidades las zonas de Bathyuriscus-Elrathina y GlossopleuraKootenia (Borrello y Pernas, 1965; Borrello, 1967). Borrello (1963) destacó, además, la gran afinidad de la fauna de trilobites de la Precordillera con las de Laurentia (véase McKerrow et al., 1992 y Vaccari, 1994), mencionada anteriormente por Poulsen (1958).

Si bien el hallazgo de Olenellus y la consiguiente edad cámbrica temprana fueron dados a conocer por Borrello (1963, 1965, 1971), la bioestratigrafía de la unidad fue establecida por Bordonaro (1986) quien definió las biozonas que abarcan desde el Cámbrico Inferior alto al Cámbrico Medio alto. Este trabajo sirvió de complemento al estudio estrati- gráfico sobre el Cámbrico de la quebrada de Zonda, donde Bordonaro (1980) redefinió la unidad y, sobre la base de contrastes litológicos, diferenció tres miembros informales. Asimismo, al conjunto de las Formaciones La Laja y Zonda lo incluyó dentro del Grupo Marquesado. Con posterioridad, Baldis y Bordonaro (1981) definieron los miembros: Calizas con chert De La Roza, Cuarcitas y lutitas EI Estero, Calizas y margas Soldano, Calizas negras Bernardino Rivadavia y Calizas oolíticas Juan Pobre. Más tarde Baldis y Bordonaro (1984) descartaron al miembro De La Roza, considerándolo una repetición tectónica del Miembro Rivadavia. Baldis y Bordonaro (1982) realizan una comparación entre el Cámbrico de la Precordillera Argentina y el de la 'Gran Cuenca' ('Great Basin') del oeste norteamericano, y mencionaron la presencia de cuatro 'Grandes Ciclos', empleando el enfoque utilizado para Aitken (1978) en el estudio del Cámbrico de las Rocallosas canadienses. En una contribución más reciente, Gomez y Astini (2005) reconocieron en la sección de la quebrada La Laja, propuesta como sección de referencia, los diferentes miembros definidos para el perfil de Zonda por Baldis y Bordonaro (1981 y 1984), agregando uno nuevo, reconocido en el tope de la sección. Dicha unidad, se denomina Miembro Las Torres y se ubica entre el Miembro Juan Pobre y la Formación Zonda (Fig. 2), habiendo sido reconocido en el resto de las secciones de la Formación La Laja aflorantes en la sierra Chica de Zonda. Con

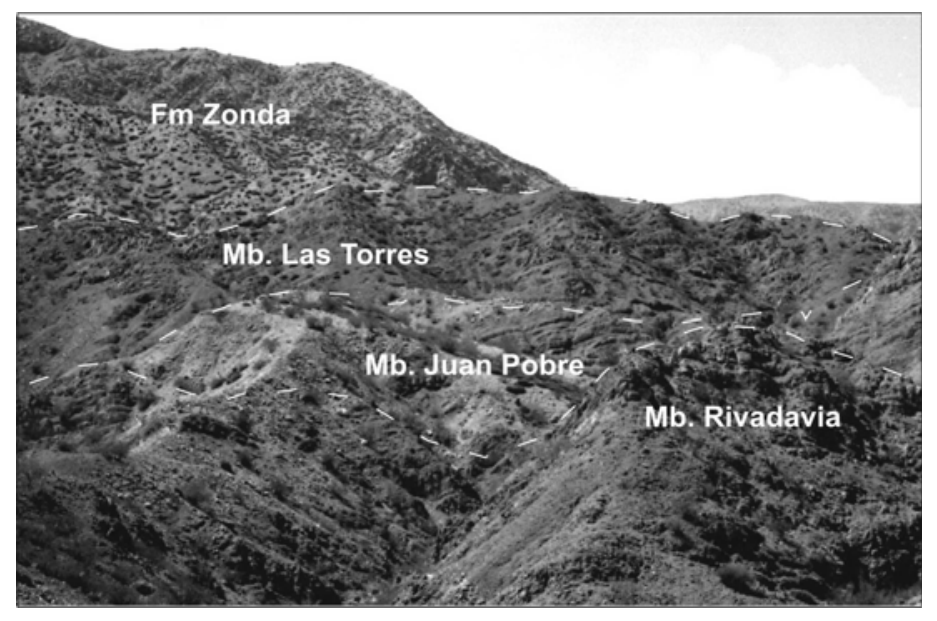

FIG. 2. Vista hacia el este en la sección de la quebrada La Laja donde pueden verse los Miembros Rivadavia, Juan Pobre y Las Torres y el contacto con la Formación Zonda. Nótese el relieve deprimido que presenta el Miembro Juan Pobre respecto a los Miembros Rivadavia y Las Torres. 
anterioridad, el tramo representado por el Miembro Las Torres fue considerado como la parte superior del Miembro Juan Pobre, sin embargo, como se demuestra en este trabajo, su separación en dos miembros diferentes se justifica dadas las notables diferencias sedimentológicas y estratigráficas.

Estudios litofaciales y aspectos petrográficos puntuales fueron dados a conocer por Baldis y Bordonaro (1985), Bercowski y Bordonaro (1987) y Bercowski et al. (1990). En trabajos de síntesis Bordonaro $(1990,1992)$ trató aspectos litoestratigráficos y bioestratigráficos de la unidad. Recientemente, Keller et al. (1998); Keller (1999), y Bordonaro (1999 y 2000) reinterpretaron la estratigrafía de la Formación La Laja señalando la existencia de un importante hiato que abarcaría las biozonas del Cámbrico Medio bajo. Esta interpretación supone la ausencia de las biozonas de Plagiura-Poliella, Albertella y Glossopleura, originalmente determinadas por Bordonaro (1980 y 1986). En este nuevo esquema la biozona de Ehmaniella se desarrollaría inmediatamente por encima de la biozona de Olenellus, permitiendo equiparar este hiato con el evento regresivo Hawke Bay (cf. Palmer y James, 1979) reconocido en Norteamérica. Keller (1999) publicó varias secciones estratigráficas de la unidad estableciendo una correlación entre perfiles ubicados en la sierra Chica de Zonda y la sierra de Villicúm. Más recientemente, Sial et al. (2001) realizaron estudios isotópicos de la unidad en la sierra de Zonda y Buggisch et al. (2003) dieron a conocer un estudio isotópico del tramo superior de la Formación La Laja y unidades suprayacentes. Bordonaro (2003 a y b) realizó una revisión general de los depósitos cámbricos de la Precordillera Argentina. Algunos aspectos de este trabajo han sido adelantados por Gomez y Astini (2001, 2004 y 2005) y Gómez et al. (2002 y 2003). Por último, Gomez et al. (2005) adelantan una curva de isótopos de $\mathrm{C}$ y $\mathrm{O}$ para la sección aflorante en la quebrada La Laja aquí analizada.

La quebrada La Laja (Fig. 1a y b) se halla a unos 25 kilómetros al sur de la quebrada de Zonda entre la quebrada de Mogotes Negros por el norte y la de quebrada Alegre al sur. Sus coordenadas son: $31^{\circ}$ $33^{\prime} 36,5^{\prime \prime S}$ y $68^{\circ} 44^{\prime} 10,3^{\prime \prime} \mathrm{W}$ y se encuentra a ca. 990 m s.n.m. Se accede a la misma desde la ruta nacional No. 20 transitando $13 \mathrm{~km}$ por un camino de ripio que se dirige hacia el sur próximo al flanco occidental de la sierra Chica de Zonda.

En esta sección, la Formación La Laja tiene un espesor de $470 \mathrm{~m}$ e inclina homoclinalmente hacia el este con valores de entre 34 y $45^{\circ}$ y rumbos submeridionales (Fig. 1b). Si bien en esta sección aflora solo la parte superior del Miembro el Estero, dado que presenta buena accesibilidad y escasa deformación (a diferencia de la sección de la quebrada de Zonda donde la unidad está afectada por intenso plegamiento), (Fig. 1b) se la propone como sección de referencia.

La Formación Zonda (Bordonaro, 1980) de edad cámbrica tardía, suprayace a esta unidad y está caracterizada por el desarrollo de ciclos perimareales de escala métrica (Keller et al., 1994), con 'dolomudstones' peloidales grises alternantes con bancos blanquecinos amarillentos con laminaciones criptoalgales. En esta región, el contacto entre ambas formaciones es neto y el marcado contraste litofacial presente a ambos lados permite interpretarlo como una paraconcordancia.

\section{METODOLOGÍA}

Se levantó una columna estratigráfica detallada de la Formación La Laja en la sección de la quebrada La Laja. A partir de los datos relevados en el campo y del análisis de muestras de mano, secciones delgadas, pulidos, y 'peels' se documentaron las principales litofacies y microfacies presentes en la unidad. La ubicación de los afloramientos y una vista panorámica de la sección en estudio pueden verse en las figuras 1 y 2 , y una columna detallada puede observarse en la figura 3. Las asociaciones de facies, sus relaciones y ubicación dentro de la columna y su interpretación paleoambiental son discutidas en el texto y resumidas en la figura 4 y en la tabla 1. En esta última se detallan las litofacies reconocidas en el campo y se mencionan sus características principales. A estas litofacies se les asigna un nombre descriptivo con el objeto de facilitar su reconocimiento en el campo y se 


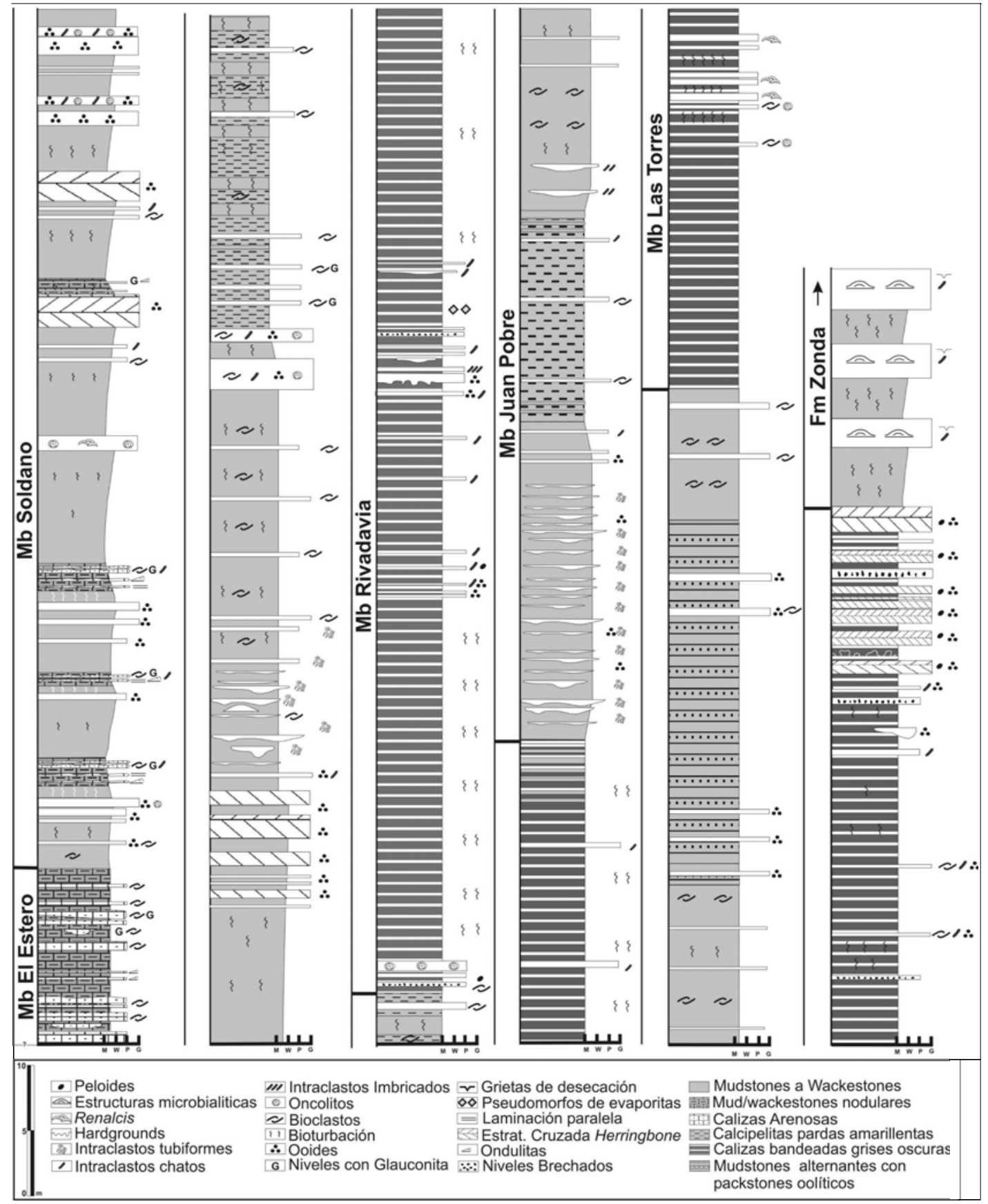

FIG. 3. Columna detallada de la Formación La Laja correspondiente a la sección de la quebrada La Laja (M = 'mudstone', W= 'wackestone', $\mathrm{P}=$ 'packstones' y $\mathrm{G}=$ ' 'grainstone').

mencionan además las microfacies constituyentes de esas litofacies. A continuación se detallan las principales microfacies reconocidas, donde se hace hincapié en la descripción objetiva de los modos texturales y composicionales. Sólo excepcional- mente se mencionan aspectos interpretativos ya que estos son tratados en el apartado donde se discuten las asociaciones de facies y los ambientes que éstas representan. Para cada microfacies se adiciona, cuando es posible, los equivalentes dentro 


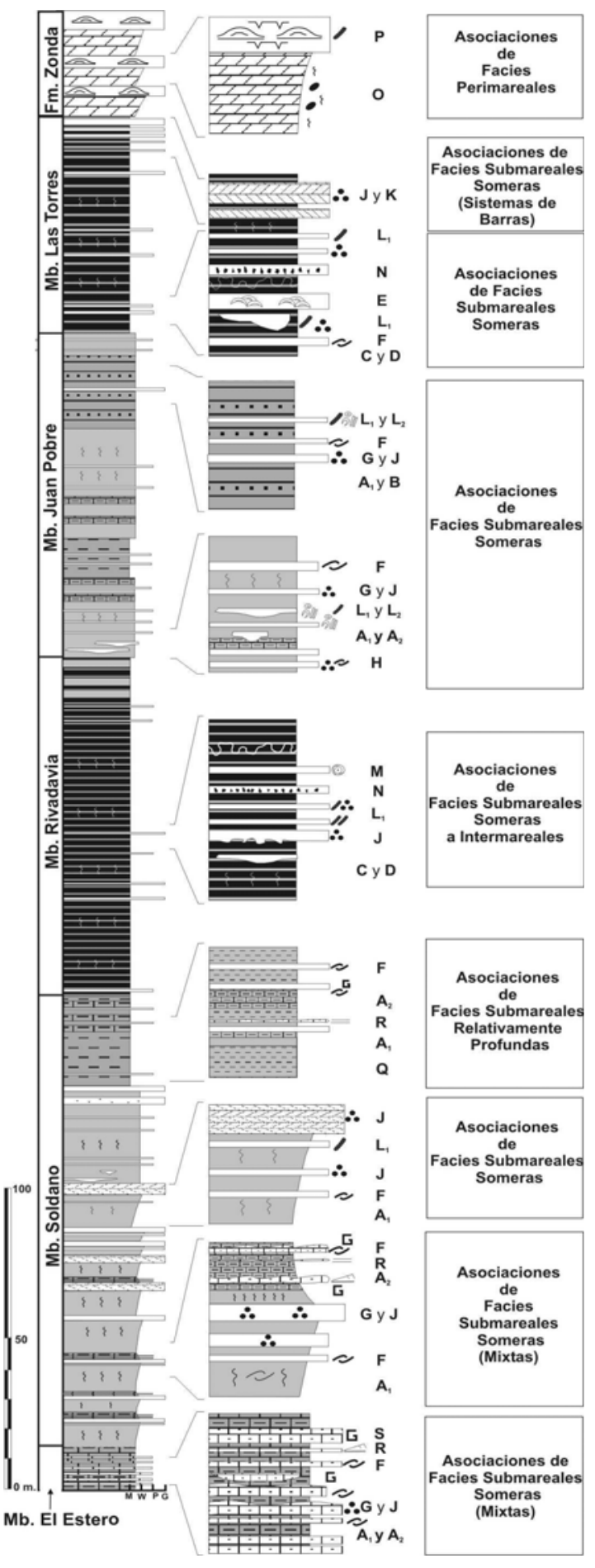

FIG. 4. Columna estratigráfica general de la Formación La Laja donde se muestran columnas sintéticas de las diferentes asociaciones de facies reconocidas, las microfacies constituyentes y su ubicación dentro de la sección (ver Tabla 1 y descripción de microfacies y sus asociaciones en el texto); símbolos de acuerdo a la figura 3). del esquema de 'microfacies standards' de Wilson (1975) y Flügel (1982), sin que esto implique que las interpretaciones sobre el significado paleoambiental de las mismas sea el mismo que el de los mencionados autores. Las 'microfacies standards' se indican en el texto y en la tabla I mediante la sigla MS y el número correspondiente. Para cuantificar el grado de bioturbación de algunos intervalos se utilizó el índice de icnofábrica (ii) (Droser y Bottjer, 1986).

\section{ESTRATIGRAFÍA}

Si bien originalmente se definieron cuatro miembros dentro de la Formación La Laja (Baldis y Bordonaro, 1984) en el presente trabajo se propone un quinto miembro para su tramo cuspidal, originalmente incluido dentro del Miembro Juan Pobre. Este último, en su definición original, incluye dos asociaciones de facies fundamentalmente distintas tanto en sus rasgos litológicos como paleoambientales, ambas de carácter cartografiable a nivel regional. Se propone entonces, redefinir el Miembro Juan Pobre (Baldis y Bordonaro, 1981 emend. Gómez y Astini, este trabajo) que se mantendrá en lo sucesivo para el tramo inferior (108 $\mathrm{m}$ ) de calizas fangosas, de color gris claro a amarillento, con intercalaciones calcareníticas y el nuevo nombre de Miembro Las Torres (Gomez y Astini, este trabajo, nom. nov.) para el tramo superior $(70 \mathrm{~m})$. Este último está representado por calizas grises oscuras y desarrollos de cuerpos oolíticos en la parte superior. Las diferencias entre ambos miembros se establecen no solo a partir del contraste litofacial, de coloración y en el patrón de estratificación sino en el perfil de meteorización y expresión topográfica (Figs. 1a y 2).

En general, la Formación La Laja (Fig. 3) constituye una unidad dominantemente calcárea que, a diferencia del resto de las que componen la sucesión cambro-ordovícica, presenta intervalos con sedimentación mixta silicoclástica-carbonática. Se puede decir que en los tramos basales e intermedios de la unidad se intercalan niveles con abundante material silicoclástico. Tales niveles van desde areniscas calcáreas y calizas arenosas, intercaladas entre calizas de estratificación delgada o calizas nodulares bioturbadas (Miembro El Estero), hasta litofacies más finas como calcipelitas y margas pardas verdosas, en ocasiones con abundante glauconita y estratofábrica nodular (parte media de 


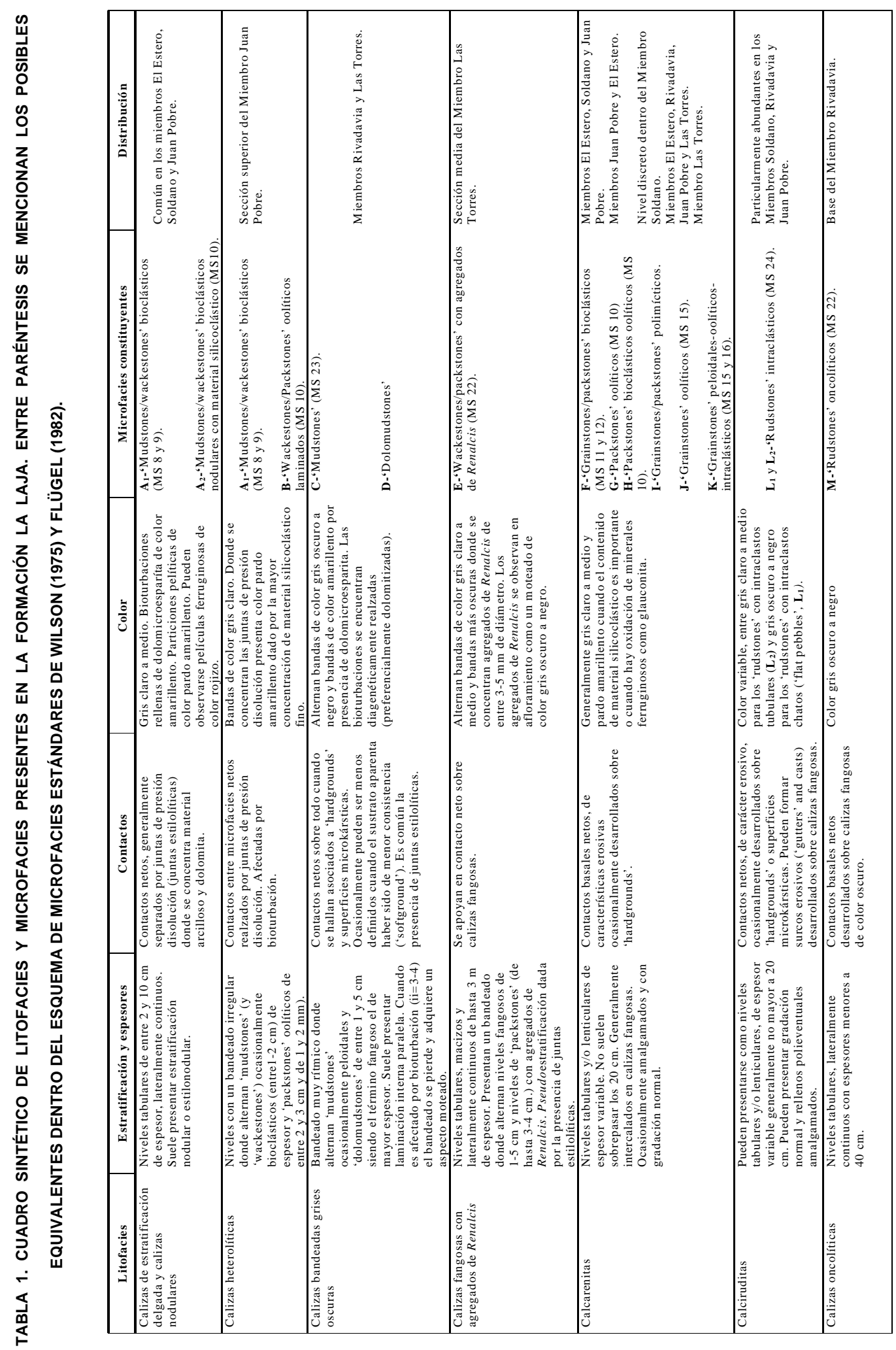




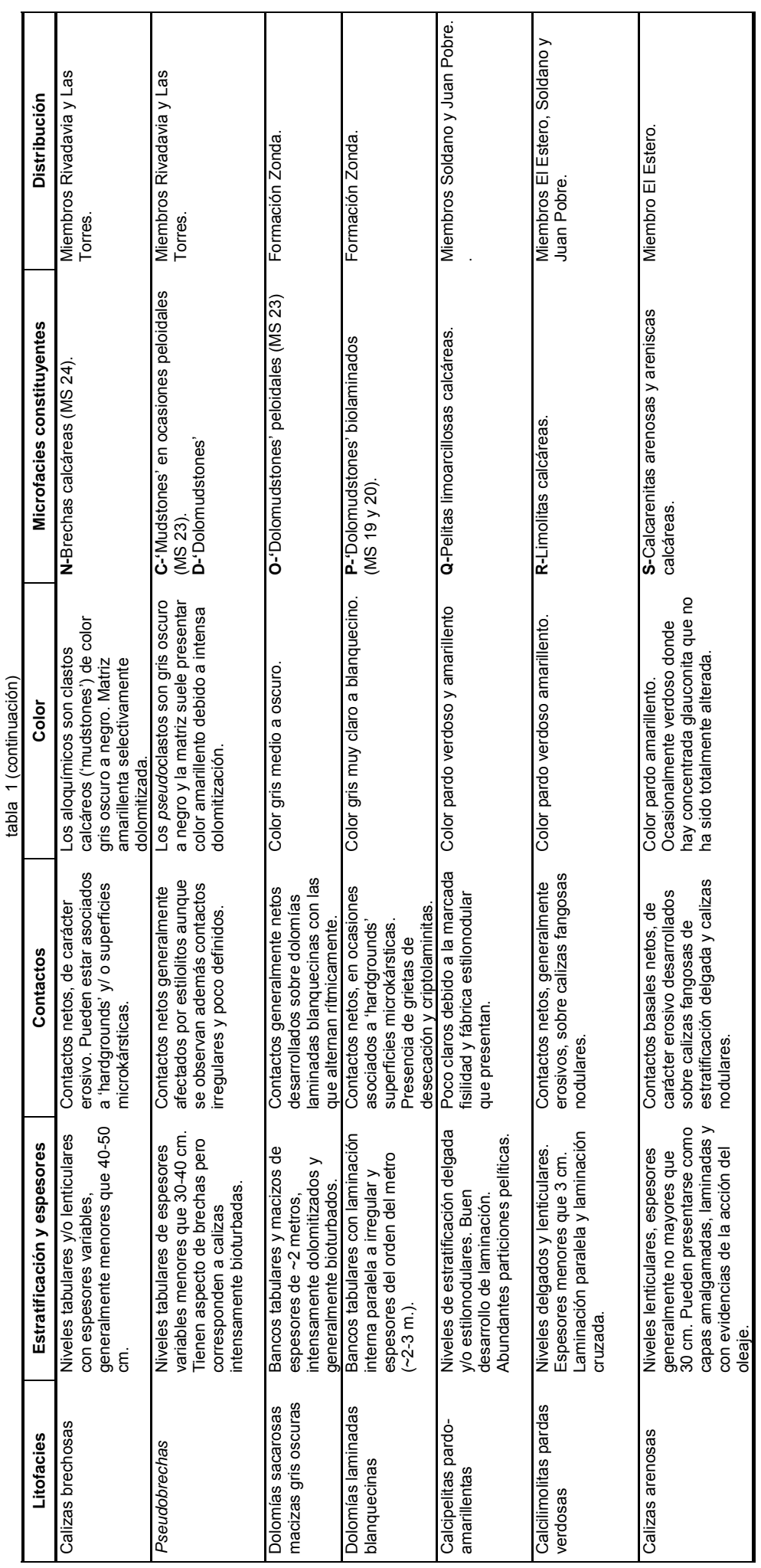



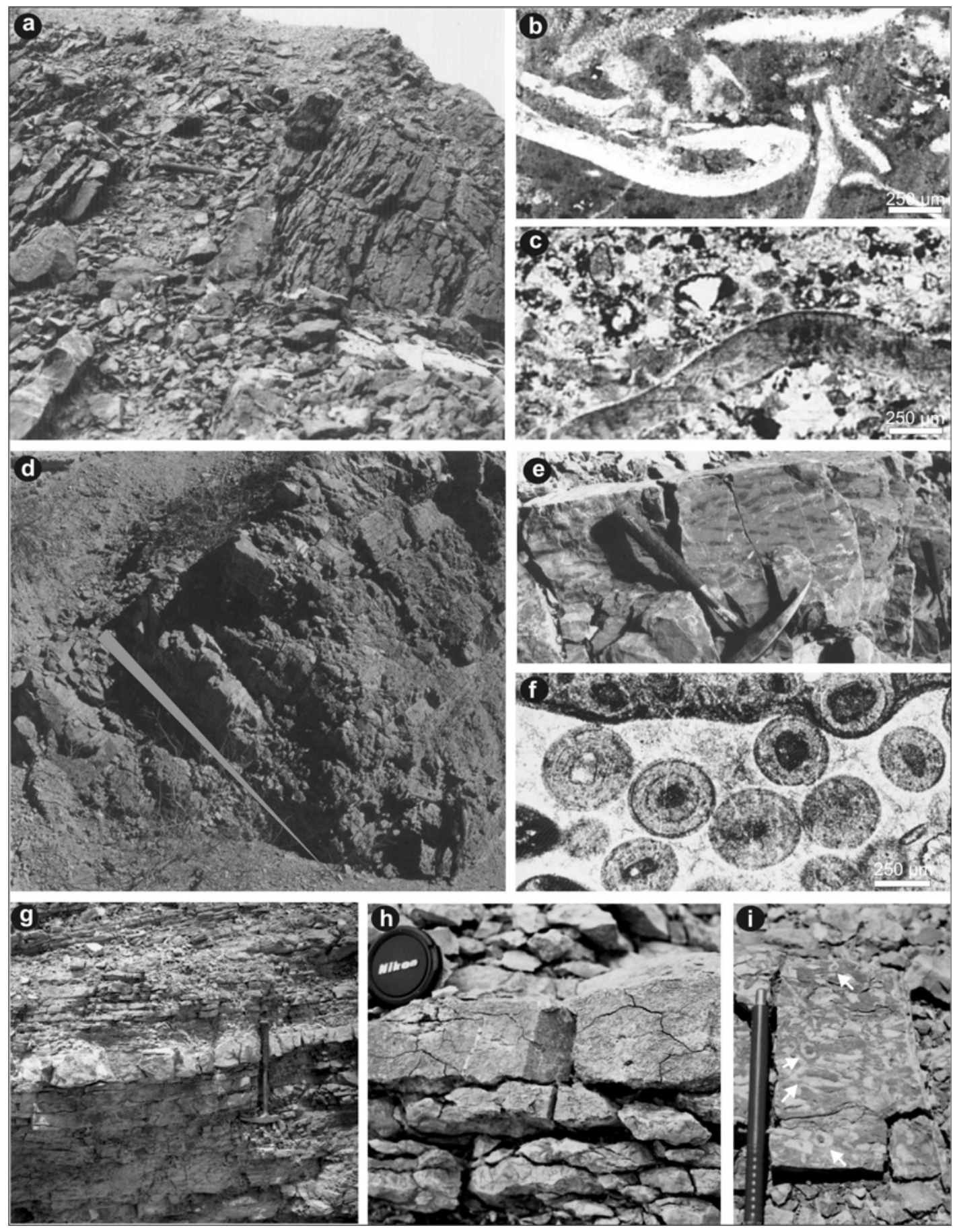

FIG. 5. (a)- Asociación de facies submareales someras mixtas correspondientes al tramo basal del Miembro Soldano; (b)-'packstone' bioclástico correspondiente al tramo basal de la Asociación de facies submareales mixtas. Los bioclastos corresponden a trilobites, (Miembro Soldano); (c)-'packstone' bioclástico correspondiente al tramo superior de la Asociación de facies submareales someras mixtas (Miembro Soldano). Nótese la abundancia de material silicoclástico tamaño limo a arena, ausente en el 'packstone' de la figura b; (d)- ciclo submareal somero (10 m de espesor), ubicado en la sección superior del Miembro Soldano; (e)- detalle del grainstone oolítico con estratificación cruzada tipo 'herringbone' que corona el ciclo de la figura d; (f)- sección delgada de un grainstone oolítico. Nótese el 'hardground' en la parte superior de la fotografía; (g)- nivel de 'packstone' intraclástico intercalado dentro de 'mudstones' y 'wackestones' bioclásticos de la microfacies $\mathrm{A}_{1}$ (ver Tabla 1), base del Miembro Soldano; (h)- detalle de nivel de 'packstone' intraclástico, base del Miembro Soldano. (i)-'packstone'intraclástico donde pueden verse diferentes secciones de intraclastos tubiformes (flecha), Miembro Juan Pobre. 
Ios Miembros Soldano y Juan Pobre). Esta asociación mixta es la que presenta una menor resistencia a la meteorización, siendo responsable de generar topografías deprimidas (Figs. 1b y 2) en comparación con los intervalos carbonáticos más puros (como los Miembros Rivadavia y Las Torres).

Dentro de las litofacies netamente carbonáticas se pueden distinguir niveles de 'mudstones' y 'wackestones' bioclásticos bioturbados y 'packstones' a grainstones oolíticos, oncolíticos y bioclásticos. Estas litofacies se disponen en ocasiones formando ciclos de somerización tal como se observa en la parte inferior del Miembro Soldano. Calizas bandeadas grises oscuras compuestas por 'mudstones' y 'wackestones' que alternan rítmicamente con 'dolomudstones' amarillentos son comunes en el Miembro Rivadavia y Miembro Las Torres, intercalados con niveles brechados y superficies microkársticas como, así también, 'packstones y rudstones' intraclásticos en ocasiones asociados a 'hardgrounds'. En el Miembro Rivadavia se observan niveles con presencia de estructuras microbialíticas de Girvanella generalmente formando agregados, oncolitos o formando parte de intraclastos, como así también, incrustaciones en diferentes aloquímicos. En el Miembro Las Torres se destacan, además, niveles de 'mudstones' y 'wackestones' gris oscuros con agregados compuestos por Renalcis (Gómez et al., 2003; y Gómez y Astini, 2005) y niveles de 'grainstones' oolíticos con estratificación cruzada.

\section{ANÁLISIS DE MICROFACIES}

'Mudstones-wackestones' bioclásticos ( $A)$ : se trata de calizas fangosas con contenido bioclástico disperso y con grados variables de bioturbación (microfacies A1, Fig. 6e). La matriz micrítica en ocasiones presenta textura grumulosa. El material bioclástico $(10-20 \%)$ se halla compuesto por fragmentos de trilobites generalmente bien preservados y espículas de esponjas. En forma subordinada contienen ooides aislados. Esta microfacies suele presentar importante contenido clástico, arcilloso a limoso. En este caso (microfacies A2) es común la presencia de juntas de presión disolución donde se concentra el material insoluble y dolomita. Estas características le otorgan en afloramiento un aspecto marcadamente nodular (Fig. 6h). MS 8 y 9.
'Wackestones-packstones' oolíticos laminados (B): se observan como bandas delgadas que oscilan en un rango de $2-3 \mathrm{~cm}$ y $1-2 \mathrm{~mm}$ de espesor (Fig. $6 f)$. En ocasiones se trata de una única hilera de ooides alineados, sólo interrumpida por efectos sobreimpuestos de bioturbación. Los ooides son de tamaños muy uniformes $(\sim 1 \mathrm{~mm})$ y presentan fábrica interna radial concéntrica, a veces poco visible al encontrarse micritizados. En algunos niveles existen individuos reemplazados por un mosaico esparítico equigranular o por un único cristal de calcita luego de haber sufrido etapas de disolución. También pueden encontrarse con reemplazos drúsicos o dados por cristales prismáticos dispuestos radialmente. En los casos en que no han sido reemplazados el núcleo está compuesto por bioclastos (trilobites) o partículas de textura micrítica (generalmente peloides). En la matriz también participan bioclástos generalmente fragmentarios correspondientes a trilobites e intraclastos bien redondeados de textura micrítica. Similar a la MS 10, pero el aloquímico dominante son ooides en vez de bioclastos.

'Mudstones' (C): 'mudstones' grises medios a oscuros con abundante materia orgánica dispuestos en bandas de entre 1 y $10 \mathrm{~cm}$ de espesor. Presentan moderada a alta bioturbación (ii=3-4) y en ocasiones adquieren fábrica moteada. Cuando se reconocen trazas discretas las bioturbaciones son de arreglo tridimensional, presentando mayor desarrollo en el plano horizontal. Los tubos que conforman estos sistemas generalmente no superan 1-2 cm de profundidad y los diámetros predominantes están entre 2 y $5 \mathrm{~mm}$. Ocasionalmente los tubos se hallan rellenos de dolomicroesparita. Al microscopio, se observan texturas homogéneas y grumulosas. Ocasionalmente exhiben pseudomorfos de evaporitas donde éstas (posiblemente yeso) han sido reemplazadas por calcita, evidenciando episodios de hipersalinidad. Cuando estos niveles se encuentran totalmente disruptos por la acción infaunal, adquieren un aspecto 'brechoso' (Fig. 5h) por lo que en la bibliografía han sido denominadas como pseudobrechas (cf. Demicco y Hardie, 1994). Estos 'mudstones' suelen presentar superficies erosivas netas o esculpidos irregulares con paredes colgantes o engolfadas propias de 'hardgrounds'. Correspondería a la MS 23.

'Dolomudstones' (D): se trata de bandas centimétricas de fangos calcáreos dolomitizados de color 

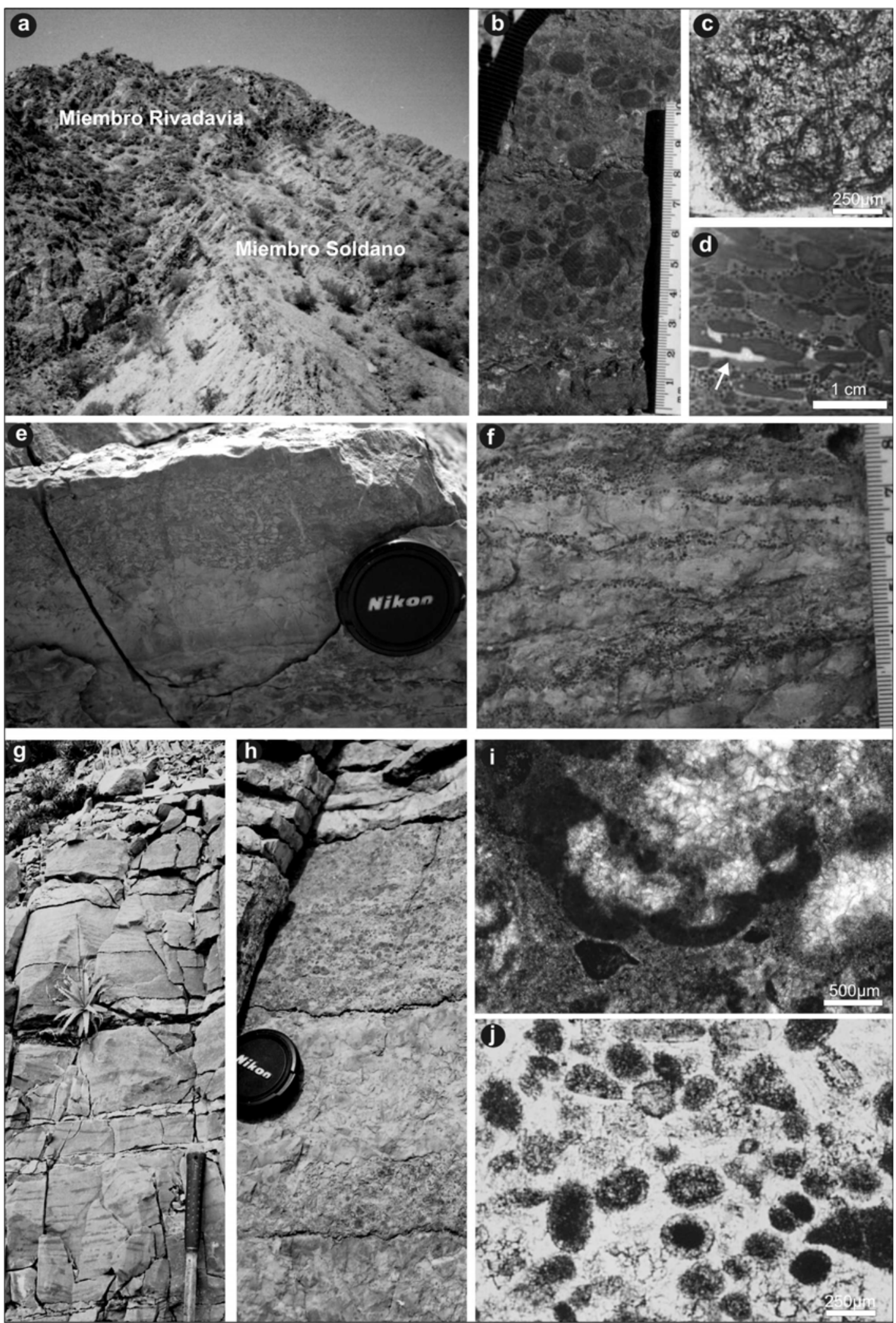
amarillento, en ocasiones con laminación paralela u ondulada, que intercala íntimamente con la microfacies C. Los cristales de dolomita tienen formas euhedrales a subhedrales, se presentan como un mosaico equigranular sobreimpuesto, y tienen tamaño limo lo que le da una apariencia de limolíta. Posiblemente se trate de 'micrograinstones' peloidales donde la intensa dolomitización dificulta el reconocimiento de otros rasgos texturales. En ocasiones esta microfacies pasa lateralmente o se encuentra intercalada con la microfacies $\mathrm{C}$ y puede estar afectada por bioturbación.

'Wackestones-packstones' con agregados de Renalcis (E): se trata de calizas fangosas con abundantes agregados de Renalcis de hasta $3 \mathrm{~mm}$ de diámetro que muy ocasionalmente se disponen en contacto. Los individuos de Renalcis se encuentran parcialmente recristalizados (Fig. 6h-i) y conforman agregados botroidales a reniformes, de formas simples, generalmente equidimensionales y sin desarrollo de ramificaciones. La cavidad interna se encuentra rellena por esparita equigranular y en ocasiones drúsica, generalmente desprovista de inclusiones. Las paredes poseen un espesor que varía entre 100-300 $\mu \mathrm{m}$ representando $\sim 1 / 4-1 / 8 \mathrm{del}$ diámetro de los sacos. Son de composición micrítica, presentando un borde externo neto, de color oscuro, y un borde interno ligeramente más difuso. Los agregados de Renalcis se disponen en bandas de pocos centímetros (aunque pueden alcanzar 10 $\mathrm{cm}$ ) que alternan con niveles más fangosos, algo bioturbados (Gómez et al., 2003 y Gómez y Astini, 2005). Se observan además escasos bioclastos correspondientes a trilobites. MS 22, en este caso no se trata de oncoides sino de agregados compuestos por Renalcis.

'Grainstones-packstones' bioclásticos (F): los bioclastos se hallan representados por trilobites
(Fig. 5b), pelmatozoos, y braquiópodos, con grados variables de preservación, y en ocasiones hay abundante glauconita. Estos niveles pueden presentar además material clástico de tamaño limo y arena (Fig. 5c), y coloración parda-amarillenta a veces producto de la oxidación de minerales ferruginosos. Suele observarse además la presencia de intraclastos chatos de 'mudstones' macizos. La glauconita se presenta como agregados de coloración verdosa con diámetros menores a 1 $\mathrm{mm}$. En algunos casos se observan granos de composición micrítica parcialmente glauconitizados. En ocasiones se encuentran concentrados en bandas de 1-2 cm por encima de superficies netas erosivas, de morfología irregular, que corresponden a 'hardgrounds'. En otras los agregados se disponen concentrados en niveles con espesores de hasta 5 $\mathrm{cm}$, produciendo características cubiertas de color ocre al oxidarse. MS 11 y 12.

'Packstones' oolíticos (G): en esta microfacies se observan ooides muy bien preservados, con contactos puntuales en una matriz micrítica parcialmente recristalizada. Los ooides tienen estructura interna tangencial con láminas concéntricas bien definidas y presentan formas y tamaños diversos, adaptándose a la geometría de las partículas que sirven de núcleo (fragmentos de ooides, bioclástos, partículas micritizadas, etc.). En su mayoría son multicapa pero también hay ooides superficiales, principalmente cuando el núcleo es muy alargado o de forma muy irregular. Los bioclastos presentes (que en ocasiones forman parte del núcleo de los ooides) están representados por fragmentos de trilobites e hyolítidos. Esta facies es una variante de la MS 10 donde los aloquímicos son ooides y no bioclastos.

'Packstones' bioclásticos oolíticos (H): son 'packstones' con fragmentos esqueletales y ooides en

FIG. 6. (a)-vista del contacto neto entre las calcipelitas de la parte superior del Miembro Soldano, y las calizas de color gris oscuro correspondientes al Miembro Rivadavia; (b)-'rudstone' oncolitico ubicado en la base del Miembro Rivadavia, inmediatamente por encima del contacto con el Miembro Soldano infrayacente. (c)- sección delgada del nivel de la figura anterior, donde se observa un agregado microbialítico compuesta por Girvanella; (d)-'packstone' intraclástico-oolítico con intraclastos chatos. Nótese la porosidad de tipo 'shelter' ocluida por calcita (flecha), Miembro Rivadavia; (e)-nivel de 'packstone' intraclástico en contacto erosivo sobre 'mudstones' y 'wackestones' bioclásticos, Miembro Juan Pobre; (f)-calizas heterolíticas compuestas por las microfacies $\mathrm{A}_{1}$ y B, sección superior del Miembro Juan Pobre; (g)-calcarenitas con estratificación cruzada de tipo 'herringbone', compuestas por 'grainstones' peloidales-oolíticos-intraclásticos (microfacies K, Tabla 1), nivel correspondiente a la sección superior del miembro Las Torres; (h)- alternancia de niveles de pseudobrechas producto de bioturbación intensa y niveles de calizas fangosas con agregados de Renalcis (microfacies E), Miembro Las Torres; (i)- sección delgada del nivel con Renalcis donde se observa un agregado botroidal parcialmente recristalizado, Miembro Las Torres. (j)-'grainstone' peloidal-oolítico-intraclástico (microfacies K) correspondiente al nivel de la figura g, Miembro Las Torres. 
proporciones similares. Los bioclastos son trilobites generalmente fragmentados. Éstos se encuentran dispuestos paralelos al plano de estratificación, con su borde cóncavo dominantemente hacia arriba. La estructura interna de los ooides no se ha preservado ya que se hallan reemplazados por esparita en bloques o por un único cristal de calcita (porosidad oomóldica posteriormente rellena). Carecen de material silicoclástico. MS 10 donde los aloquímicos dominates son ooides y bioclastos. 'Grainstones-packstones' polimícticos (I): Son calcarenitas con gran heterogeneidad composicional. Los aloquímicos predominantes están representados por bioclastos, intraclastos, oncoides, peloides y de manera subordinada ooides, dispuestos de manera caótica o sin un ordenamiento aparente. Puede observarse además la presencia de material silicoclástico tamaño limo. Es común en esta microfacies la presencia de agregados de Girvanella, formando intraclastos e incrustaciones alrededor de bioclástos, peloides e intraclastos. Los bioclastos corresponden principalmente a restos fragmentarios de trilobites y pelmatozoos. Si bien los bioclastos se encuentran fragmentados, cuando éstos se encuentran recubiertos por Girvanella presentan mejor grado de preservación, lo que indicaría que algunos fueron recubiertos previamente a su movilización, transporte y abrasión. Participan además intraclastos con abundante contenido de limo clástico y escasos agregados de Renalcis dentro de intraclastos.

'Grainstones' oolíticos (J): se trata de calcarenitas limpias compuestas por oolitas con tamaños uniformes dispuestas en capas gradadas o con estratificación cruzada (Fig. 5e). En general, los ooides son circulares a ligeramente elípticos y tienen estructura concéntrica (Fig. 5f). A veces están micritizadas, parcial o totalmente recristalizadas y reemplazadas por calcita o por dolomita. En este último caso la dolomita reemplaza selectivamente los ooides. En casos de fábrica densa pueden tener contactos suturados asociados a juntas estilolíticas. Puede haber hasta un $3 \%$ de material detrítico subangular a subredondeado, tamaño limo a arena muy fina. Se observa además, aunque de manera muy subordinada la presencia de bioclastos, enteros o fragmentados (braquiópodos, trilobites). Es común la presencia de superficies netas e irregulares, desarrolladas sobre los 'grainstones' oolíticos conformando hardgrounds
(Fig. 5f) que se evidencian por truncamientos afectando tanto a cemento como a las oolitas. MS 15.

'Grainstones' peloidales-oolíticos-intraclásticos (K): se trata de calcarenitas con peloides y ocasionales ooides e intraclastos, a veces recristalizados y/o dolomitizados. En los ooides la fábrica interna se puede observar solo en forma difusa debido a que se hallan en gran parte micritizados. Se observan además bandas de $1 \mathrm{~cm}$ afectadas por presión disolución con peloides y ooides deformados y contactos suturados. Las bandas estilolíticas coinciden con la laminación interna que presenta esta microfacies. Intraclastos micríticos y bioclastos correspondientes a trilobites, están muy subordinados (Fig. 6j). Es una variante representada por una mezcla de las MS 15 y 16 .

'Rudstones' intraclásticos (L): son calciruditas donde se reconocen dos tipos de intraclastos diferentes (Gomez y Astini 2004):

L1-Intraclastos planares del tipo clastos chatos ('flat pebbles'), en ocasiones internamente laminados, constituidos por 'mudstones', 'wackestones' y 'packstones' bioclásticos u oolíticos, como así también grainstones oolíticos. En el caso de los constituidos por 'wackestones' y 'packstones' bioclásticos, estos presentan laminación paralela y los bioclástos corresponden a fragmentos de trilobites. Se han observado además, intraclastos con abundante material detrítico. En general, tienen 2-3 cm de largo, son planares y pueden disponerse ya sea de manera caótica, paralelos al plano de estratificación o imbricados con una matriz de fango calcáreo intersticial. Suelen presentar gradación normal, y es común la presencia de porosidad de tipo 'shelter' ocluida por cemento esparítico. En ocasiones, además de intraclastos dentro de la matriz, hay ooides en proporciones variables (Fig. 6d). Estos ooides son circulares a elipsoidales y presentan fábrica interna laminar concéntrica en general pobremente preservada ya que hay importante micritización. Es una variante de la MS 24 donde los aloquímicos dominantes son intraclastos y ocasionalmente ooides.

L2-Intraclastos de formas muy irregulares, con secciones tabulares, circulares a elípticas hasta en medialuna que asemejan diferentes secciones de estructuras tubiformes, enteras o fragmentadas (Fig. 5i). Las paredes poseen bordes internos y externos netos y planos, aunque las externas 
pueden ser más irregulares. Son de composición micrítica y/o microesparítica, de color más claro que la matriz en que se encuentran inmersos o la que constituye el relleno interno. Estos intraclastos se hallan compuestos por material micrítico, sin presencia de aloquímicos, y se encuentran rellenos de micrita o de cemento esparítico, en ocasiones con estructuras geopetales. En general, el diámetro externo de los tubos (DE) varía entre 4,5 y $12 \mathrm{~mm}$ y el diámetro interno (DI) entre 2 y $7 \mathrm{~mm}$. No obstante, las diferentes capas muestran tamaños relativamente homogéneos, donde la relación promedio DI/DE es de 0,57, y el espesor de las paredes $(E P=D E-D I / 2)$ varía entre 0,75 y $3,2 \mathrm{~mm}$. El núcleo o relleno interno se encuentra sistemáticamente centrado respecto al eje del intraclasto. La presencia de rellenos geopetales en la cavidad interna de los intraclastos indicaría que fueron transportados predominantemente como estructuras abiertas. Variante de la MS 24 donde los aloquímicos dominantes son intraclastos.

'Rudstones' oncolíticos (M): oncolitos de hasta 2$3 \mathrm{~cm}$ de diámetro, de formas redondeadas a elípticas (Fig. 6b), con láminas planas de crecimiento concéntrico y simétrico y compuestas por Girvanella (oncoides Tipo C, cf. Logan et al. , 1964; Radwánski y Szulczewski, 1966). Presentan partículas carbonáticas como núcleo, ya sean peloides, bioclastos fragmentados, intraclastos, etc. Girvanella se encuentra asimismo formando intraclastos y/o agregados enrollados sin estructuración interna (Fig. 6c) o incrustando partículas. La matriz en que se encuentran inmersos los oncolitos está constituida por un 'packstone' a 'grainstone' peloidal con bioclastos e intraclastos. Estos últimos internamente presentan textura de 'mudstones' y los bioclastos corresponden a trilobites. MS 22.

Brechas calcáreas $(\mathrm{N})$ : dentro de esta microfacies se incluye a brechas intraformacionales que incluyen intraclastos de textura micrítica y formas irregulares, angulosas o deflecadas, generalmente flotando en un fango calcáreo de color amarillento. Los clastos micríticos tienen tamaños de hasta 3 $\mathrm{cm}$. Estas brechas se disponen sobre superficies irregulares donde se observa que el brechamiento ha ocurrido in situ (microkarst?), afectando a calizas bandeadas grises oscuras representadas por las microfacies C y D. Variante de la MS 24 evidenciando escaso transporte.

'Dolomudstones' peloidales (0): 'mudstones' de color gris oscuro, aspecto macizo, textura sacaroide (producto de dolomitización intensa) y moderada a alta bioturbación (ii=3-4). En ocasiones, se observan relictos de texturas peloidales y/o grumulosas, visibles de manera difusa. En general, la intensa dolomitización dificulta la observación de la mayoría de los rasgos texturales primarios. Variante de la MS 23.

'Dolomudstones' biolaminados (P): se trata de 'dolomudstones' de color gris claro a blanquecino con una profusa laminación criptomicrobial tanto regular como irregular (sensu Kennard y James 1986), porosidad fenestral ocluída por calcita, pequeños domos estromatolíticos (pequeños estromatolitos LLH), grietas de desecación y acumulaciones de intraclastos chatos internamente laminados. Las láminas presentan textura peloidal y/o grumulosa y carecen de material silicoclástico. Hay dolomitización intensa que dificulta el reconocimiento de otros rasgos texturales. Variante de las MS 19 y 20 dolomitizadas.

Pelitas limoarcillosas calcáreas (Q): se trata de fangolitas y limoarcilitas con fuerte reacción calcárea, laminación paralela y moderada bioturbación. Presentan una marcada fisilidad que oblitera la laminación primaria, fábrica estilonodular y color pardo-verdoso amarillento en ocasiones producto de oxidación de glauconita y otros minerales ferruginosos.

Limolitas calcáreas laminadas(R): se trata de limolitas calcáreos de coloración pardo verdosa con una marcada abundancia de micas (tanto biotita y muscovita). Los granos de cuarzo varían entre limo fino y grueso (subangulosos) y se encuentran en una matriz micrítica que en ocasiones presenta textura grumulosa y/o peloidal. Tiene laminación paralela y ocasionalmente laminación cruzada. Suelen intercalarse delgadas particiones pelíticas. Calcarenitas arenosas y areniscas calcáreas (S): se trata de transiciones entre arenitas híbridas y calizas arenosas con porcentajes variables de material silicoclástico que alcanzan el $80-90 \%$ en bandas de 1-2 cm. En promedio, los silicoclásticos no superan valores del $40 \%$ siendo el resto componentes granulares (fundamentalmente bioclastos) parcialmente disueltos o micritizados. La fracción arena presenta granulometría entre limo grueso y arena media y es de composición arcósica a subfeldespática. Texturalmente, el material es bastante inmaduro (partículas angulares a subangulares) y 
son frecuentes las micas. Pueden presentar abundante glauconita y oxidación superficial lo que le da un color ocre amarillento. El cemento es esparítico de grano medio a grueso. Entre las estructuras mas destacadas se cuenta la laminación paralela a veces dispuesta en conjuntos con bajo ángulo, en la que alternan láminas con diferentes porcentajes de clásticos y laminación cruzada simétrica producto de flujos oscilatorios.

\section{ASOCIACIONES DE FACIES}

\section{ASOCIACIÓN DE FACIES SUBMAREALES RELATIVA- MENTE PROFUNDAS}

Esta asociación se caracteriza por la presencia de importante contenido silicoclástico fino, incluyendo niveles calcipelíticos y calcilimolíticos, y niveles de 'mudstones' a 'wackestones' bioclásticos de colores pardos amarillentos por alteración de glauconita y otros minerales ferruginosos (microfacies Q, R, A1 y A2). La estratificación delgada y laminación interna es, a veces, obliterada por fenómenos de compactación otorgándole el aspecto nodular que comúnmente desarrollan (Figs. 5g-h). En general, se observa una alternancia de niveles nodulares con otros de aspecto más macizo, probablemente debido a variaciones en la proporción de material silicoclástico y/o en el grado de cementación. Esto generó respuestas diferentes a los procesos de compactación y meteorización. Dentro de esta asociación se destacan intercalaciones tabulares con bases netas erosivas de 'packstones' a 'grainstones' bioclásticos gradados (microfacies F), sin retrabajo de oleaje en el tope. Esta asociación se observa en dos intervalos de 26 y 15 m presentes en la parte superior del Miembro Soldano (Fig. 6a) y en el tercio medio del Miembro Juan Pobre. Las intercalaciones de 'packstones' a 'grainstones' con faunas relativamente diversificadas y fragmentadas representarían depósitos de tormenta distales. Esto se infiere debido a que carecen de los términos cuspidales típicos de tempestitas proximales (e.g., ondulitas simétricas) y a que no se observan amalgamaciones entre eventos (e.g., Aigner, 1985). No obstante, es preciso señalar que en general, el grado de bioturbación es lo suficientemente elevado como para desvirtuar los términos superiores de un depósito de tormenta. Un elemento de juicio independiente es la común presencia de abundante glauconita cuyo crecimiento estaría vinculado a bajas tasas de sedimentación en ambientes relativamente reductores y de baja energía (Odin y Matter, 1981). Para esta asociación de facies, ambientes submareales relativamente profundos, de baja energía y por debajo del nivel de base del oleaje de tormentas son inferidos fundamentalmente debido a la granulometría fina de los materiales, la presencia de laminación paralela correspondiente quizás a bajo régimen de flujo, la carencia de estructuras sedimentarias producto de acción del oleaje o mareas, y la presencia de tempestitas distales. Asimismo, la presencia de glauconita indicaría cierta condensación de la sedimentación y sería un producto de diagénesis temprana, generándose en la interfase agua sedimento o inmediatamente debajo, donde sustratos relativamente porosos se encuentran en contacto con el agua de mar en situación reductora. Debe mencionarse, que otros autores han registrado ejemplos en los que abundante glauconita se desarrolla en ambientes marinos someros, con altas tasas de sedimentación y niveles de energía elevados (Chafetz y Reid, 2000). Éste no sería nuestro caso ya que, como ha sido mencionado, no se han registrado facies indicadoras de condiciones de alta energía por lo que puede descartarse dicho origen y por el contrario, la presencia de una alta proporción de depósitos ricos en fango implica un predominio de condiciones tranquilas. El dominio de clásticos finos podría deberse a que un influjo de material terrígeno en suspensión habría inhibido ('poisoning') la productividad carbonática ( e.g., Kendall y Schlager, 1981; Schlager, 1989). Alternativamente, puede deberse a que la misma fue sumergida rápidamente, disminuyendo así la productividad carbonática. Las características mencionadas para esta asociación de facies, son consideradas comunes en ambientes submareales de plataforma ya sea en depósitos modernos o en el registro geológico (e.g., Wilson y Jordan, 1983). Asimismo, depósitos similares han sido descritos por Calvet y Tucker (1988), Choi y Simo, (1998); Osleger y Read (1991) entre otros, e interpretados como depósitos de plataforma media a externa. 


\section{ASOCIACIONES DE FACIES SUBMAREALES SOMERAS}

Se incluyen aquí aquellas asociaciones de facies carentes de contenido silicoclástico significativo y pertenecientes al medio submareal somero. Estas incluyen:

a) Niveles de apariencia cíclica, de entre 5-15 m de espesor ubicados la mitad inferior del Miembro Soldano (Fig. 5d). Los tramos inferiores están compuestos por 'mudstones' y 'wackestones' bioclásticos (microfacies A1) y presentan intercalaciones de 'packstones' bioclásticos e intraclásticos y 'grainstones' oolíticos (microfacies F, L1 y J). 'Grainstones' oolíticos de hasta $4 \mathrm{~m}$ de espesor y estratificación cruzada de tipo bimodal coronan estos intervalos (Fig. 5e-f). Los términos inferiores de esta asociación de facies se habrían depositado en un ambiente submareal somero, por debajo del nivel de base del oleaje de buen tiempo, con depósitos eventuales de tempestitas. Los 'grainstones' oolíticos que coronan los ciclos corresponderían a depósitos de barras o 'shoals' que progradan sobre los niveles anteriores, producto de somerización gradual. La influencia de la acción del oleaje y mareas sobre la parte superior de estos cuerpos oolíticos, esta representada por la presencia de 'sets' (15 cm de espesor cada uno) de estratificación cruzada de tipo bimodal ('herringbone'). No se hallaron evidencias de exposición subaérea en el tope de estos ciclos. A diferencia de otros ciclos observados en el Miembro Soldano, estos no presentan importante contenido silicoclástico, lo que indica que las barreras se construyeron en un ambiente alejado de la línea de costa o al abrigo del influjo clástico continental. La progradación o migración cíclica de cuerpos oolíticos sobre facies submareales más profundas, indicarían una disminución en el espacio de acomodación. Los procesos de redistribución de sedimentos por acción del oleaje y mareas, junto a variaciones relativas del nivel del mar habrían mantenido las condiciones necesarias para el desarrollo de ciclos submareales someros, evitando así la agradación hacia condiciones intersupramareales. Esto es inferido por la ausencia de evidencias de exposición subaérea, diagénesis meteórica, pedogénesis incipiente, etc., que indiquen depositación intermareal o supramareal. Procesos de redistribución activa de sedimentos han sido considerados por Osleger (1991) como críticos para el desarrollo de ciclos submareales. Ciclos de características y espesores similares a los aquí descritos han sido mencionados por Aigner (1985) para depósitos del Triásico Medio de Alemania, Osleger (1991) y Osleger y Read, (1991) para el Cámbrico Superior, de Utah y Nevada, Elrick y Read, (1991) para el Mississippiano de Wyoming y Montana, Srinivasan y Walker (1993) y Rankey et al. (1994) para el Grupo Conasauga, del Cámbrico Medio y Superior de los Apalaches.

b) Calizas bandeadas oscuras, representados por 'mudstones' grises oscuros y 'dolomudstones' (microfacies C y D), brechas (microfacies N) y pseudobrechas calcáreas (Fig. 6h), 'packstones' bioclásticos y oolíticos, 'rudstones' intraclásticos (microfacies F, G y L1) y niveles con agregados de Renalcis (microfacies E, Fig. 6h-i) pueden observarse en el tercio inferior y medio del Miembro Las Torres. Hacia la parte superior se hacen comunes intercalaciones de 'grainstones' peloidales y oolíticos (Fig. 6j), ya sea formando tempestitas, como así también sistemas de barras (Fig. 6g) con notable desarrollo de estratificación cruzada (microfacies $\mathbf{J}$ y $\mathbf{K}$ ). La asociación de facies observada en la sección inferior y media, sobre la base de las características ya mencionadas, es interpretada como correspondiente a ambientes submareales muy someros, con evidencias recurrentes de exposición subaérea. Los niveles de grainstones peloidales y oolíticos, observados en la parte superior del miembro, representan ambientes submareales someros y de alta energía. Éstos, corresponden a sistemas de barras o 'shoals' sometidos a la acción del oleaje y mareas, lo que puede ser inferido por la presencia de estratificación cruzada de tipo 'herringbone'.

c) Depósitos submareales sin arreglo cíclico evidente, pueden observarse en la parte media del Miembro Soldano y en la mitad inferior del Miembro Juan Pobre (Fig. 3). Éstos se hallan caracterizados por 'mudstones' y 'wackestones' bioturbados (microfacies A1 y A2), abundantes intercalaciones de niveles de 'grainstones' y 'packstones' bioclásticos (microfacies F), y 'rudstones' intraclásticos como los de las figuras $5 \mathrm{~g}-\mathrm{h}$ (microfacies L1 y L2, Fig. 5i), 'packstones' bioclasticos-oolíticos, y de manera subordinada 'packstones' a 'grainstones' oolíticos (microfacies H, G y J). Estos niveles de 'packstones', 'grainstones' 
y'rudstones' se presentan como capas generalmente lenticulares, con gradación normal, bases erosivas y espesores de hasta $20 \mathrm{~cm}$, y se interpretan como tempestitas. En el caso del Miembro Soldano se destaca,además, un nivel discreto de 2 a3 m de espesor de 'grainstones/packstones' polimícticos (microfacies I), formado por capas amalgamadas de hasta $50 \mathrm{~cm}$ de espesor. Algunos de los niveles de capas de tormentas mencionados, se encuentran compuestos por 'rudstones' intraclásticos, cuyos intraclastos presentan formas comparables con diferentes secciones de estructuras tubiformes (microfacies L2, Fig. 5i). Se trataría de concentraciones mecánicas de bioturbaciones, cementadas tempranamente, fragmentadas y transportadas durante tormentas, siendo posteriormente depositadas durante la etapa menguante de la tormenta (Gómez y Astini, 2004). Demicco y Hardie, (1994) mencionaron, para ambientes modernos, depósitos de tubos de Callianassa tempranamente cementados y formados en condiciones análogas. Esta asociación de facies se interpreta como depositada en ambientes submareales someros, donde predominaba la depositación de fangos carbonáticos afectados por la actividad infaunal. La presencia de capas de 'packstones' y 'grainstones' gradados y con bases erosivas serían indicadoras de condiciones de mayor energía debido a tormentas episódicas que afectaron la plataforma. Como puede observarse en dos intervalos dentro de los Miembros Soldano y Juan Pobre, algunos de los rudstones intraclásticos constituyen el relleno de surcos erosivos de sección transversal en forma de 'V' y/o 'U' ('gutters' y 'casts') $y$ en ocasiones con rellenos polieventuales amalgamados. Niveles similares a estos han sido también observados al norte, en la parte inferior del Miembro Juan Pobre (en la quebrada de Juan Pobre), como así también en la sección aflorante en Cerro Tres Marías. Estos surcos generalmente son atribuidos a flujos turbulentos helicoidales originados por tormentas en ambientes submareales, y rellenados durante etapas menguantes (Kreisa, 1981; Aigner, 1985; Myrow, 1992, 1994). Bridges (1972) describió este tipo de estructuras como producto de exposición subaérea y Duringer y Vecsei (1998) mencionan estructuras de corte y relleno producidas por emersión, aunque no descartan un origen subácueo. En nuestro caso se intercalan en facies fangosas bioturbadas interpretadas como depositadas en ambientes submareales someros. No obstante, un origen producto de etapas de exposición subaérea no puede descartarse. Estudios de mayor detalle permitirán definir si estos surcos se desarrollaron en ambiente subácueo o si representan períodos de exposición de la plataforma asociados a una caída relativa del nivel del mar.

d) Facies heterolíticas laminadas donde alternan bandas de $\sim 1 \mathrm{~cm}$ de espesor de 'mudstones' pardo grisáceos, ocasionalmente bioclásticos (microfacies A1, Fig. 6f) con 'packstones' oolíticos laminares (microfacies B, Fig. 6f) pueden observarse en el tramo superior del Miembro Juan Pobre (Fig. 3). Intercalan en el conjunto capas tabulares de 'packstones' (F, G y L1 y L2) y grainstones oolíticos (microfacies J). Esta asociación correspondería a ambientes submareales someros restringidos, donde predominaba la alternancia de 'mudstones' con láminas ricas en oolitas que representaría la sedimentación de fondo en situaciones próximas a barras oolíticas actuando como fuentes de ooides. Dicha alternancia implica un aporte intermitente de oolitas que se redistribuían en la periferia de las barras, mientras que las capas tabulares de 'grainstones' y 'packstones' indicarían redepositación masiva durante episodios de tormenta. Un ejemplo actual similar lo constituyen sistemas de barras o shoals oolíticos observados al noroeste de la isla de Andros (Bahamas), donde dichos sistemas habrían marginado ambientes submareales someros de baja energía en situación de retrobarrera (Tucker y Wright, 1990). En esta situación tanto las tormentas que afectaron las barras como el permanente efecto del oleaje generaron dispersión y remoción intermitentemente aportando aloquímicos (ooides) a la región del 'backshoal'.

\section{ASOCIACIÓN DE FACIES SUBMAREALES SOMERAS MIXTAS}

Esta asociación, registrada en el Miembro El Estero, varia de manera gradual entre dos extremos representados por facies arenosas mixtas con material terrígeno relativamente grueso y facies submareales carentes de dicho contenido clástico como las presentes en la base del Miembro Soldano.

El intervalo basal de esta asociación, se destaca por la presencia de paquetes de calcarenitas arenosas y areniscas calcáreas (microfacies S) y 
limolitas calcáreas (microfacies R), intercaladas en 'mudstones' a 'wackestones' bioclásticos, en ocasiones nodulares (microfacies A1 y A2). Se intercalan en forma subordinada niveles de 'packstones' y 'grainstones' bioclásticos y oolíticos (microfacies F, G y J). Esta asociación se presenta dentro del Miembro El Estero. Los niveles arenosos se presentan en forma de capas generalmente lenticulares, de hasta $30 \mathrm{~cm}$ de espesor, en ocasiones amalgamadas. Estos niveles presentan granulometrías relativamente gruesas (limo grueso a arena media), bases erosivas y evidencias de retrabajo de oleaje, y son aquí interpretados como tempestitas proximales (Aigner, 1985). Depósitos similares en los que se intercalan areniscas gradadas en calizas micríticas han sido mencionados por Tucker, (1982). La asociación de facies ya descrita puede asignarse a ambientes submareales someros, en los que intermitentemente hubo influjo clástico relativamente grueso depositado principalmente en etapas de tormentas. El material terrígeno (rico en feldespatos) habría sido aportado desde áreas cratónicas, durante etapas de pasaje de sedimentos ('bypass') que permitieron el acceso de materiales detríticos desde zonas costeras hacia la plataforma. Esta modalidad es comúnmente gatillada y favorecida por descensos relativos del nivel del mar que favorecen una 'mezcla episódica' y desarrollo de depósitos mixtos ('punctuated mixing', cf. Mount, 1984).

En la parte inferior y media del Miembro Soldano (Fig. 3) alternan niveles con escaso contenido silicoclástico y niveles donde éste es abundante conformando el conjunto paquetes de hasta $10 \mathrm{~m}$ de espesor. Los primeros se hallan compuestos por 'mudstones' y 'wackestones' bioclásticos bioturbados (microfacies A1), con intercalaciones de 'packstones' y 'grainstones' oolíticos (microfacies G y J), bioclásticos (microfacies F, Fig. 5b), intraclásticos (microfacies L 1 ), y a veces oncolíticos, con arreglo estratocreciente (alcanzando un espesor máximo de $90 \mathrm{~cm}$ ). Generalmente alternan niveles poco bioturbados y niveles donde la bioturbación es más intensa. Hacia el tope suele presentar un nivel de entre 50 y $60 \mathrm{~cm}$ de 'mudstones' a 'wackestones' con una fábrica moteada producto de bioturbación. Este nivel se destaca por una disminución en el diámetro de las bioturbaciones. Cubriendo los niveles antes mencionados hay 'mudstones' y 'wackestones' nodulares (microfacies
A2) con abundantes intercalaciones de 'packstones' y 'grainstones' bioclásticos de color pardo amarillento (niveles de hasta $25 \mathrm{~cm}$ de espesor, microfacies F, Fig. $5 \mathrm{c})$, y capas delgadas $(<5 \mathrm{~cm})$, tabulares y lenticulares de limolitas calcáreas laminadas (microfacies R) ocasionalmente con evidencias de retrabajo de oleaje. Es común además la presencia de glauconita. Como ha sido mencionado, las litofacies de la parte inferior presentan escaso contenido clástico, mientras que en la parte superior éste es abundante (ver 'packstones' bioclásticos de las figuras $5 b-c)$. Este intervalo, en su conjunto, es interpretado como correspondiente a eventos de somerización, en los que inicialmente se depositaron las litofacies relativamente puras en un ambiente submareal somero, desconectado del influjo clástico con intercalaciones eventuales de tempestitas. Luego, debido a la gradual somerización, se activa el influjo de material terrígeno costero, depositándose el intervalo superior, con abundante contenido clástico y evidencias de retrabajo de oleaje. No se observan hacia el tope rasgos que indiquen exposición subaérea o depositación intermareal, ya que, grietas de desecación, estructuras pedogéneticas, laminaciones algales, u otros rasgos típicos de estos ambientes están ausentes. En este caso, y a diferencia de lo mencionado para la asociación submareal profunda, la presencia de niveles con abundante glauconita asociados a facies someras con evidencias de retrabajo de oleaje permite considerar un origen asociado a condiciones de mayor energía similar al propuesto por Chafetz y Reid (2000).

\section{ASOCIACIONES DE FACIES SUBMAREALES SOMERAS A INTERMAREALES}

Facies submareales someras a intermareales, con evidencias recurrentes de exposición subaérea, se hacen comunes en los miembros Rivadavia y Las Torres, como así también en la suprayacente Formación Zonda. En esta última, ciclos perimareales típicos de llanuras de mareas, comparables con los descritos por Keller et al. (1989) y Cañas (1990) para unidades cámbricas de la Precordillera se hallan bien representados (Fig. 3).

El Miembro Rivadavia (Figs. 3 y 6a) se halla caracterizado por calizas bandeadas grises oscuras, donde alternan 'mudstones' ocasionalmente peloidales (microfacies C), con 'dolomudstones' de color 
amarillento (microfacies D) a veces laminados. Hay además intercalaciones abundantes de 'rudstones' intraclásticos (Fig. 6d), intraclásticosoolíticos, y oncolíticos (microfacies L1, y M, Fig. $6 b$ ), niveles de brechas (microfacies $\mathrm{N}$ ) y pseudobrechas y niveles de 'grainstones' oolíticos (microfacies $\mathbf{J}$ ). Evidencias recurrentes de exposición subaérea son comunes y son inferidas por la abundancia de rudstones intraclásticos de variada geometría, superficies 'microkarsticas' y 'hardgrounds'. La presencia de niveles con pseudomorfos de evaporitas muestra condiciones de hipersalinidad en un ambiente muy somero, restringido y sujeto a evaporación intensa probablemente en un clima árido. Asimismo, Girvanella (Fig. 6c) formando oncolitos y agregados podría indicar que localmente existieron condiciones restringidas, tranquilas a poca profundidad (Flügel, 1982; Peryt, 1983; Tucker y Wright, 1990). Lentes de packstones a rudstones intraclásticos que forman el relleno de canales someros, a veces con estratificación epsilon, son interpretados como rellenos de pequeños canales mareales. También, son un buen indicio de facies intermareales, brechas calcáreas vinculadas a exposición subaérea. Esta asociación posee grados variables de bioturbación que va desde baja a moderada hallándose los sistemas de galerías selectivamente dolomitizados (Gómez y Astini, 2001). En ocasiones se observa una alternancia de niveles desprovistos de bioturbación con niveles bioturbados. Facies de calizas bandeadas similares a las del Miembro Rivadavia son interpretadas por numerosos autores como correspondientes a este tipo de ambientes (veáse Reineck y Singh, 1980; Demicco, 1984; Pratt y James, 1986; Osleger y Read, 1991, y Demicco y Hardie, 1994, entre otros).

Por encima del Miembro Las Torres, y en contacto abrupto, se desarrollan dolomías con un arreglo cíclico, correspondientes a la Formación Zonda. Los ciclos, de 4 a $6 \mathrm{~m}$ de espesor, están representados por la alternancia de dolomías sacaroides grises oscuras y dolomías laminadas blanquecinas (microfacies $\mathbf{O}$ y $\mathbf{P}$, constituidas por 'dolomudstones' peloidales y 'dolomudstones' biolaminados, respectivamente). Es común, la presencia de estructuras microestromatolíticas, grietas de desecación, conglomerados de clastos chatos, y porosidad fenestral. Estos niveles corresponden a ciclos perimareales típicos de llanuras de mareas (Hardie, 1986; Demicco y Hardie,
1994). Las características mencionadas pueden observarse ya sea en el registro geológico, como así también en ambientes modernos, y son interpretadas como generadas en ambientes perimareales (veáse Shinn, 1983; Tucker y Wright, 1990, entre otros). La importante dolomitización existente constituye probablemente un rasgo diagenético temprano, ya que ésta se haya particularmente desarrollada en los niveles superiores de la columna, caracterizada por el predominio de facies intermareales y supramareales. El hecho de que la presencia de abundantes dolomías coincida con un cambio ambiental importante reflejado por la abrupta transición hacia facies intersupramareales de la Formación Zonda, indicaría que el fenómeno de dolomitización se halla relacionado con procesos vadosos propios de estos ambientes (Shinn, 1983) y no que se trata de dolomitización producto de diagénesis profunda.

\section{CONSIDERACIONES SOBRE PATRONES CÍCLICOS}

Si bien no se han desarrollado estudios sistemáticos de ciclicidad en las formaciones La Laja y Zonda, del arreglo vertical que presentan (Figs. 3 y 4 ) se puede inferir que hay ciclos de diferentes órdenes sobreimpuestos, indicando así una historia depositacional repetida. Los patrones cíclicos comúnmente observados en depósitos carbonáticos tienen como controles de primer orden eustatismo, tasa de subsidencia, y tasa de sedimentación, y de su interacción se infieren curvas relativas del nivel del mar (e.g., Goldhammer et al., 1990 y referencias allí citadas). Asimismo, como se ha observado en el registro geológico y en modelos computacionales, de gran importancia en el desarrollo de patrones cíclicos observados en depósitos carbonáticos son procesos intrínsecos a los diferentes subambientes sin necesidad de que entren en juego controles externos (Ginsburg, 1971; Pratt y James, 1986; Spencer y Demicco, 1989; Burgess, 2001; Burgess, et al., 2001; Burgess y Wright, 2003). Como destaca Goldhammer et al. (1993), la presencia de unidades con arreglo cíclico puede ser el resultado de la interacción compleja de procesos alocíclicos y autocíclicos, actuando a diferentes escalas y generando así diferentes órdenes de ciclicidad sobreimpuestos. No obstante, a través de procesos estocásticos pueden igualmente generarse secuencias que presenten 
un aparente ordenamiento interno (Wilkinson et al., 1996, 1997, 1999).

La alternancia cíclica a gran escala entre depósitos carbonáticos y silicoclásticos cámbricos ha sido ampliamente documentada en sucesiones laurénticas (Aitken, 1978; Palmer, 1971; Hinze y Robinson, 1975; Palmer y Halley, 1979; Chow y James, 1987; Koerschner y Read, 1989; Srinivasan y Walker, 1993; Cowan y James, 1993; Spencer y Demicco, 2002, entre otros). Aitken (1978), debido a su gran escala, llamó a esta alternancia 'Grandes Ciclos' ('Grand Cycles'), diferenciándolos de los ciclos de somerización de escala menor, con espesores del orden del metro, tan frecuentes en depósitos carbonáticos. Se considera actualmente que la duración de los 'Grandes Ciclos' es comparable a la de ciclos de 2 y $3^{\circ}$ orden. Dentro de esta alternancia cíclica de gran escala, común en depósitos paleozoicos laurénticos, se reconocen ciclos de menor escala o ciclos de alta frecuencia sobreimpuestos (Osleger y Read,1993; Koerschner y Read 1989 , entre otros), de $4^{\circ}, 5^{\circ}$ y $6^{\circ}$ orden, con períodos entre 500 y 10 ky. (cf. Vail et al., 1991; parasecuencias de Van Wagoner et al., 1988).

Baldis y Bordonaro (1982), sobre la base de contrastes litológicos y empleando el mismo enfoque de Aitken (1978), reconocieron 4 'Grandes Ciclos' comprendiendo las Formaciones La Laja, Zonda y La Flecha y los compararon con ciclos similares de la Formación Carrara de la Gran Cuenca ('Great Basin') del sudoeste de Norteamérica. Keller et al. (1998) y Keller (1999), empleando conceptos de estratigrafía secuencial, definieron para la Formación La Laja y base de la Formación Zonda cinco ciclos de $3^{\circ}$ orden. Como ha sido mencionado, la Formación La Laja y Formación Zonda presentan un arreglo estratigráfico más complejo que el mencionado en trabajos previos, donde la superposición de diferentes órdenes de ciclicidad es evidente. Debe destacarse que el enfoque utilizado por Aitken (1978) para sucesiones de Laurentia y por Baldis y Bordonaro (1982) para unidades de Precordillera resulta demasiado simple y carece de significado si se tiene en cuenta la complejidad de los sistemas depositacionales carbonáticos y mixtos y el nivel de resolución estratigráfica con que se trabaja actualmente. Muchos 'Grandes Ciclos' reconocidos no cumplen con los requisitos inicialmente propuestos por Aitken (1978), donde cada ciclo representaría un evento de sedimentación continua, de carácter transgresivo-regresivo (Aitken, 1978; Chow y James, 1987; Srinivasan y Walker, 1993). Por ejemplo, han sido mencionados grandes ciclos cuyos hemiciclos presentan discontinuidades internas de rango estratigráfico secuencial (e.g., Osleger y Montañez, 1996), o donde no hay cambios ambientales importantes, sino cambios graduales en la proporción de material terrígeno (Cooper, 1989). Como ejemplo, puede mencionarse el caso del segundo ciclo reconocido por Baldis y Bordonaro (1982) que se inicia con los niveles mixtos de la parte superior del Miembro Soldano y culmina con niveles carbonáticos del Miembro Rivadavia. El contacto entre ambos hemiciclos es abrupto (Fig. 6a), lo que resulta inconsistente con el enfoque de Aitken (1978). Asimismo, estos autores ubican la base del mismo ciclo en la parte media del Miembro Soldano, contradiciendo el aspecto de 'relativa homogeneidad litológica' que requiere la definición formal de miembros. Esto justificaría una revisión del Miembro Soldano ya que incluye asociaciones de litofacies muy contrastadas.

La presente separación de ciclos mayores sin connotación genética o estratigráfico-secuencial sólo considera la alternancia de litofacies composicionalmente diferentes, producto de la participación o no de aporte terrígeno a la cuenca, por analogía con la literatura clásica, donde la base de un ciclo se ubica en concordancia con la aparición de litofacies mixtas y el tope en el paquete puramente carbonático. Las características de los contactos entre ciclos y/o hemiciclos son variables en cada caso, pudiendo ser graduales o abruptos. Esta es la principal diferencia con los ciclos reconocidos por Aitken (1978) y utilizados por Baldis y Bordonaro (1982). Sólo adquieren importancia genética o estratigrafico-secuencial cuando son interpretadas en función de las asociaciones de facies que separan y los ambientes que estas representan, independientemente de que tengan o no contenido clástico que puede deberse a innumerables factores. En consecuencia, debido a que los Grandes Ciclos (según el enfoque tradicional) carecen de significado genético claro y sólo representan una alternancia de asociaciones de facies composicionalmente contrastadas, en el presente trabajo su reconocimiento se realiza con el objeto de resaltar similitudes que a gran escala presenta con el Cámbrico de Laurentia, pero que 


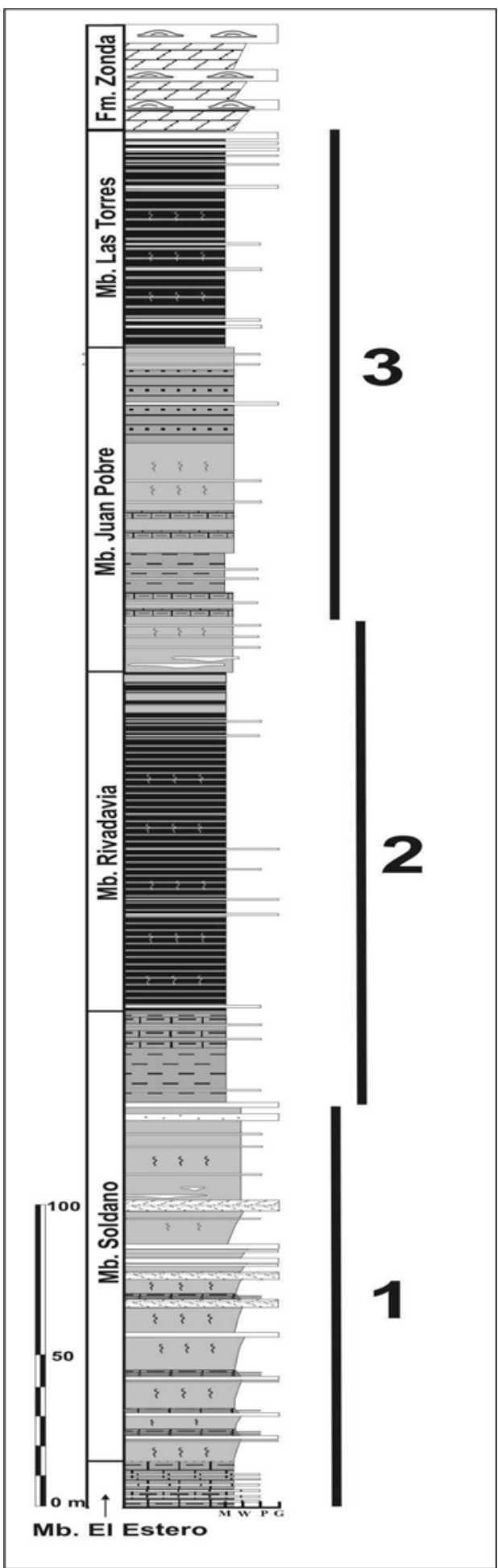

FIG. 7. Columna estratigráfica generalizada de la Formación La Laja donde se observan 3 ciclos de gran escala donde alternan litofacies mixtas y carbonáticas. dadas las limitaciones cronoestratigráficas no permiten establecer correlaciones regionales hasta no entender bien el funcionamiento y la arquitectura de los sistemas carbonáticos respectivos.

Dentro de la sección de referencia descrita para la Formación La Laja se reconocen 3 alternancias silicoclástico-carbonáticas (Fig. 7). Teniendo en cuenta que la estratigrafía de la Formación La Laja se desarrolló entre la biozona de Olenellus (Miembro El Estero) y el límite entre las biozonas de Bolaspidella y Cedaria (contacto entre las Formaciones La Laja y Zonda) (Bordonaro, 2003), la misma representa un rango temporal de $\sim 10 \mathrm{M}$.a. Puede entonces considerarse que los ciclos reconocidos corresponderían a fluctuaciones de $2^{\circ}$ y/o $3^{\circ}$ orden (cf. Vail et al., 1991), incluso considerando la presencia de la discordancia Hawke Bay entre los Miembros El Estero y Soldano (Keller et al., 1998). Aunque aún no se conoce su verdadera magnitud temporal en la Precordillera dicho hiatus comprendería las biozonas de Plagiura/Poliella, Albertella y Glossopleura (Bordonaro, 1999; 2003a $y b)$.

Un primer ciclo se reconoce (Fig. 7) entre la base de la sección y el contacto neto con la asociación de facies submareales relativamente profundas dentro del Miembro Soldano (Fig. 3). El hemiciclo basal, sin base expuesta, se encuentra compuesto por la asociación de facies submareales someras mixtas observadas en los primeros $65 \mathrm{~m}$ desde la base del perfil incluyendo lo que aflora del Miembro El Estero y la base del Miembro Soldano. De manera transicional pasa al hemiciclo carbonático representado por $85 \mathrm{~m}$ de la asociación de facies submareal somera desarrollada en la sección media del Miembro Soldano. El contacto con el siguiente ciclo es neto y se encuentra marcado por $26 \mathrm{~m}$ de la asociación de facies submareales relativamente profundas de la parte superior del Miembro Soldano. El hemiciclo carbonático está marcado por el abrupto desarrollo del Miembro Rivadavia, representado por $120 \mathrm{~m}$ de las asociaciones de facies submareales someras a intermareales (Figs. 4 y 6a). Este último abarca el Miembro Rivadavia más $\sim 25 \mathrm{~m}$ de la sección basal del Miembro Juan Pobre. El contacto neto entre los hemiciclos del segundo ciclo representaría alguna superficie importante desde el punto de vista estratigráfico secuencial, ya que separa facies submareales relativamente profundas con importan- 
te contenido silicoclástico y facies perimareales carentes del mismo, implicando una rápida reorganización de los sistemas depositacionales. El contacto con el tercer ciclo (Fig. 7) está evidenciado por el pasaje de facies submareales someras a facies submareales profundas conjuntamente con un aumento gradual del contenido de material terrígeno. El hemiciclo inferior comprendería la sección media del Miembro Juan Pobre $(\sim 15 \mathrm{~m})$, representado por facies mixtas submareales profundas. El hemiciclo carbonático desarrollado en aparente continuidad corresponde al tramo superior del Miembro Juan Pobre y la totalidad del Miembro Las Torres representados por facies submareales someras. En contacto neto se apoyan las dolomías de la Formación Zonda que indicarían un fuerte contraste paleoambiental, mediando una superficie estratigráficamente significativa. La misma sería producto una rápida reorganización de los sistemas depositacionales, representando una discontinuidad estratigráfica (paraconcordancia).

$\mathrm{Al}$ arreglo en ciclos mayores se sobreimponen ciclos de somerización de escala métrica (probablemente 4 y/o $5^{\circ}$ orden). Éstos pueden observarse dentro de la Formación La Laja (ciclos submareales del Miembro Soldano) y dentro de la Formación Zonda, donde ciclicidad de alta frecuencia es más evidente. Estos últimos corresponden a ciclos perimareales típicos, que contrastan notablemente con los observados en la Formación La Laja.

Los ciclos submareales del Miembro Soldano presentan evidencias de la acción de oleaje y mareas indicando que los procesos de erosión y redistribución de sedimentos habrían sido de gran importancia en su configuración. Si bien éstos son controles en esencia 'autocíclicos', el modelo autocíclico de Ginsburg (1971) no es aplicable ya que implica la depositación de facies intermareales coronando estos ciclos. Considerando que las tasas de sedimentación comunes en ambientes carbonáticos permitirían la rápida agradación hasta zonas donde se depositan facies intermareales, superando la generación de espacio de acomodación, la carencia de facies intermareales coronando los ciclos implica que erosión submarina o redistribución de sedimentos habrían inhibido la agradación (cf. Osleger, 1991). Esto indicaría que procesos autocíclicos han sido importantes en su configuración. De todas maneras es necesario que estos procesos hayan actuado en conjunto con controles externos que crearon periódicamente el espacio de acomodación necesario para la generación de estos ciclos. En el caso de los ciclos de alta frecuencia de la Formación Zonda, los mismos presentan facies intermareales en el tope, y muestran buenas evidencias que indican exposición subaérea. Lo antes dicho permite inferir que variaciones relativas del nivel del mar de alta frecuencia pueden haber afectado en gran medida a estos depósitos. En este caso, el modelo progradacional de Ginsburg (1971) puede ser aplicado aunque no puede descartarse que controles alocíclicos hayan tenido un efecto importante ya que notables improntas de exposición subaérea sólo se producen si hay una caída relativa del nivel del mar (Lehrman y Goldhammer, 1999; Burgess, 2001). Como mencionara Goldhammer et al. (1993) para el Ordovícico Inferior de Texas, la falta de masa continentales en regiones polares durante el Cámbrico y Ordovícico temprano puede haber minimizado el efecto glacio-eustático. Teniendo en cuenta lo antes dicho, los procesos autocíclicos pueden haber sido realzados teniendo así un mayor control en el desarrollo de estos depósitos. Estudios de mayor detalle a lo largo de diferentes secciones se hallan en curso con el objeto de resolver estas cuestiones.

\section{CONCLUSIONES}

De la revisión sedimentológica y estratigráfica de la Formación La Laja, Cámbrico Inferior y Medio de la Precordillera Argentina, se establecen las siguientes conclusiones:

Se reconocieron 19 microfacies agrupadas en
4 asociaciones de facies principales, con numerosas variantes, que permitieron realizar el análisis paleoambiental de la unidad.

Las asociaciones de facies reconocidas corresponden a ambientes marinos someros de naturaleza 
mixta carbonático-silicoclástica. El espectro representado por dicha formación va desde ambientes submareales relativamente profundos, afectados ocasionalmente por tormentas, a ambientes submareales mucho más someros, bajo el efecto del oleaje y mareas. No hay evidencias, al menos en la sección de la quebrada La Laja, de desarrollo de facies más profundas, correspondientes a ambiente de talud o cuenca marina profunda. Si bien predominan litofacies carbonáticas relativamente 'puras' (donde el contenido de material silicoclástico se halla muy subordinado), en ocasiones hubo importante aporte de material silicoclástico, lo que generó en ciertos intervalos el desarrollo de facies mixtas. Depósitos perimareales, con evidencias recurrentes de exposición subaerea, condiciones marinas restringidas, desarrollo de laminaciones algales, etc., se hacen comunes en la parte media y superior de la columna. Estos alcanzan su mayor desarrollo durante la depositación de la Formación Zonda, en la que ciclos perimareales típicos son observados en contacto neto sobre el Miembro Las Torres. La tendencia general de la Formación La Laja es somerizante, se observa el predominio de depósitos submareales en la parte inferior y media, y depósitos supramareales hacia la parte superior. A pesar de esto, hubo episodios puntuales en los que hay signos de profundización importante con abundante aporte de material terrígeno. Durante estos episodios la sedimentación carbonática se vio sensiblemente disminuida, como en el caso de la sección superior del Miembro Soldano, donde predomina la sedimentación silicoclástica. Asimismo, hubo etapas de rápida somerización, como la ocurrida durante la depositación de los miembros Rivadavia y la Formación Zonda. El marcado contraste entre el intervalo basal cíclico del Miembro Soldano y el intervalo con importante contenido silicoclástico de la parte superior justificarían una separación desde el punto de vista litoestratigráfico que permitiría afinar aspectos de correlación estratigráfica y aclarar la nomenclatura existente.

La alternancia de ciclos de gran escala en depósitos carbonáticos y mixtos, sumado a la presencia de ciclos de somerización submareales y ciclos perimareales de alta frecuencia y escala métrica, refleja que hubo distintos órdenes de ciclicidad sobreimpuestos durante la depositación de la Formación La Laja y su pasaje a la Formación Zonda, evidenciando una historia depositacional compleja.

\section{AGRADECIMIENTOS}

Se agradecen los comentarios de los revisores los Dres. B. Pratt (University of Saskatchewan, Canadá), J. Le Roux (Universidad de Chile) y O. Bordonaro (Universidad Nacional de San JuanConicet, Argentina) sobre distintos aspectos de este trabajo. Asimismo, se agradece a los geólogos S. De La Puente (Centro Regional de Investigaciones Científicas y Técnicas (CRICyT), Mendoza, Argentina) y R. Foglia (Centro de
Investigaciones Paleobiológicas y Universidad Nacional de Córdoba, Argentina) y M. Breccia y a las estudiantes L. Sorrentino y E. Bertoni (Universidad Nacional de Córdoba) por su ayuda brindada durante el desarrollo de las tareas de campo. El presente estudio es subsidiado por el Consejo Nacional de Ciencia y Tecnología (PIP 02971/ 2001CONICET) y la Agencia Nacional de Promoción Científica y Tecnológica (PICT 07-11741/2002).

\section{REFERENCIAS}

Aceñolaza, F.G.; Miller, H.; Toselli, A.J. 2002. ProterozoicEarly Paleozoic evolution in western South Americaa discussion. Tectonophysics 354: 121-137.

Aigner, T. 1985. Storm depositional systems: Dynamic stratigraphy in modern and ancient shallow-marine sequences. Lecture Notes in Earth Sciences, SpringerVerlag 3: $174 \mathrm{p}$.
Astini, R.A.; Benedetto J.L.; Vaccari, N.E. 1995. The early Paleozoic evolution of the Argentine Precordillera as a Laurentian rifted, drifted and collided terrane: A geodynamical model. Geological Society of America, Bulletin 107: 253-273.

Astini, R.A.; Ramos, V.A.; Benedetto, J.L.; Vaccari, N.E.; Cañas, F.L. 1996. La Precordillera: Un terreno exótico 
a Gondwana. In Congreso Geológico Argentino, No. 13 y Congreso de Exploración de Hidrocarburos, No. 3, Actas 5: 293-324. Buenos Aires.

Aitken, J.D. 1978. Revised models for depositional Grand Cycles, Cambrian of the Southern Rocky Mountains, Canadá. Bulletin of Canadian Petroleum Geology 26: 515-542.

Baldis, B.A.; Bordonaro, O.L. 1981. Evolución de facies carbonáticas en la cuenca cámbrica de la Precordillera de San Juan. In Congreso Geológico Argentino, No. 8, Actas 2: 385-397.

Baldis, B.A.; Bordonaro, O.L. 1984. Cámbrico y Ordovícico en la sierra Chica de Zonda y Cerro Pedernal, Provincia de San Juan. Génesis del margen continental en la Precordillera. In Congreso Geológico Argentino, No. 9, Actas 4: 190-207. San Carlos de Bariloche.

Baldis, B.A.; Bordonaro, O.L. 1985. Variaciones de facies en la cuenca cámbrica de la Precordillera Argentina y su relación con la génesis del borde continental. In Congreso Latinoamericano de Geología, No. 6, Actas 1: 31-42. Bogotá, Colombia.

Baldis, B.; Peralta, S.H.; Villegas, R. 1989. Esquematizaciones de una posible transcurrencia del terrane de Precordillera como fragmento continental procedente de áreas pampeano-bonaerenses. Correlación Geológica 5 (8): 1-100.

Benedetto, J.L. 2004. The allochthony of the Argentine Precordillera ten years later (1993-2003): A new paleobiogeographic test of the microcontinental model. Gondwana Research 7 (4): 1027-1039.

Bercowski, F.; Bordonaro, O.L. 1987. Algas calcáreas cámbricas en la Formación la Laja, San Juan, Argentina. In Congreso Geológico Argentino No. 10, Actas 3: 57-60. San Miguel de Tucumán.

Bercowski, F.; Keller, M.; Bordonaro, O.L. 1990. Litofacies de la Formación La Laja (Cámbrico) en la sierra Chica de Zonda, Precordillera Sanjuanina, Argentina. In Reunión Argentina de Sedimentología No. 2, Actas 1: 31-36. San Juan.

Bond, G.C.; Nickeson, P.A.; Kominz, M.A. 1984. Breakup of a supercontinent between $625 \mathrm{Ma}$ and $555 \mathrm{Ma}$ : New evidence and implications for continental histories. Earth and Planetary Science Letters 70: 325-345.

Bordonaro, O.L. 1980. El Cámbrico en la quebrada de Zonda, Provincia de San Juan. Revista de la Asociación Geológica Argentina 35 (1): 26-40.

Bordonaro, O.L. 1986. Bioestratigrafía del Cámbrico Inferior de San Juan. In Congreso Argentino de Paleontología y Bioestratigrafía No. 4, Actas 1: 1927. Mendoza.

Bordonaro, O.L. 1990. El sistema Cámbrico de la Provincia de San Juan. In Congreso Geológico Argentino No. 11, Relatorio: 18-30. San Juan.

Bordonaro, O.L. 1992. El Cámbrico de Sudamérica. In Paleozoico Inferior de Iberoamérica (Gutiérrez Marco, J.C. et. al.; editores). Universidad de Extremadura:
69-84. Madrid.

Bordonaro, O.L. 1999. Hiatus faunístico (Evento Hawke Bay?) entre el Cámbrico Inferior y Medio en la Formación La Laja, Precordillera de San Juan. In Congreso Geológico Argentino No. 14, Actas 1:45. Salta, Argentina.

Bordonaro, O.L. 2000. Review of the Argentine Precordillera Cambrian System. In Cambrian of the Southern Edge (Aceñolaza, G.F.; Peralta, S.; editors), Miscelánea 6: 80-81. Tucumán.

Bordonaro, O.L. 2003a. Review of the Cambrian stratigraphy of the Argentine Precordillera. Geológica, Acta 1 (1): 11-21.

Bordonaro, O.L. 2003b. Evolución paleoambiental y paleogeográfica de la cuenca cámbrica de la Precordillera Argentina. Revista de la Asociación Geológica Argentina 58 (3): 329-346.

Borrello, A.V. 1962. Caliza La Laja (Cámbrico Medio de San Juan). Notas Comunicaciones Investigaciones Científicas 2: 3-8. La Plata.

Borrello, A.V. 1963. Fremontella Inopinata n.sp. del Cámbrico de Argentina. Ameghiniana 3 (2): 51-55.

Borrello, A.V. 1965. Sobre la presencia del Cámbrico Inferior olenellidiano en la sierra de Zonda, Precordillera de San Juan. Ameghiniana 3: 313-318.

Borrello, A.V. 1967. El género Elrathina en el Cámbrico de San Juan. Reunión de la Conmemoración de la Sociedad Paleontológica Argentina, No. 1 (1): 1-3. Buenos Aires.

Borrello, A.V. 1971. The Cambrian of South America. In Cambrian of the New World. Lower Paleozoic Rocks of the World (Holland, C.H.; editor). Wiley Science 1: 385-438. New York.

Borrello, A.V.; Pernas, R.D. 1965. Sobre la presencia del género Kootenia en el Cámbrico de San Juan. In Jornadas Geológicas Argentinas No. 2, Actas 1: 57 62. Buenos Aires.

Bridges, P.H. 1972. The significance of tool marks on a Silurian erosional furrow. Geological Magazine 109: 405-410.

Buggisch, W.; Keller, M.; Lenhert, O. 2003. Carbon isotope record of the Late Cambrian to Early Ordovician carbonates of the Argentine Precordillera. Palaeogeography, Palaeoclimatology, Palaeoecology 195: 357-373.

Burgess, P.M. 2001. Modeling carbonate sequence development without relative sea-level oscillations. Geology 29 (12): 1127-1130.

Burgess, P.M.; Wright, V.P.; Emery, D. 2001. Numerical forward modelling of peritidal carbonate parasequence development: implications for outcrop interpretation. Basin Research 13: 1-16.

Burgess, P.M.; Wright, V.P. 2003. Numerical forward modelling of carbonate platform dynamics: an evaluation of complexity and completeness in carbonate strata. Journal of Sedimentary Research 73 (5): 637652. 
Calvet, F.; Tucker, M.E. 1988. Outer ramp carbonate cycles in the Upper Muschelkalk, Catalan Basin, NE Spain. Sedimentary Geology 57: 185-198.

Cañas, F.L. 1990. Biolititos microbianos (microbialitos) del Cámbrico tardío, Formación Los Sapitos, Precordillera de La Rioja. In Reunión Argentina de Sedimentología No. 3, Actas: 81-86. San Juan.

Chafetz, H.S.; Reid, A. 2000. Syndepositional shallowwater precipitation of glauconitic minerals. Sedimentary Geology 136: 29-42.

Choi, Y.S.; Simo, J.A. 1998. Ramp facies and sequence stratigraphic models in an epeiric sea: the Upper Ordovician mixed carbonate-siliciclastic Glenwood and Platteville Formations, Wisconsin, USA. In Carbonate ramps (Wright, V.P.; Burchette, T.P.; editors). Geological Society of London, Special Publications 149: 437-456.

Chow, N.; James, N.P. 1987. Cambrian Grand Cycles: a northern Appalachian perspective. Geological Society of America, Bulletin 98: 418-429.

Cooper, J.D. 1989. Does the Upper Cambrian Dunderberg Shale-Halfpint carbonate couplet in the southern Great Basin qualify as a grand cycle? In Cavalcade of Carbonates, Pacific Section (Cooper, J.D.; editor). Society of Economic Paleontologists and Mineralogists 61: $77-85$

Cowan, C.A.; James, N.P. 1993. The interactions of sealevel change, terrigenous sediment influx, and carbonate productivity as controls on Upper Cambrian Grand Cycles of western Newfoundland, Canadá. Geological Society of América, Bulletin 105: 15761590.

Dalla Salda, L.H.; Cingolani, C.A.; Varela, R. 1992. Early Paleozoic orogenic belt of the Andes in Southwestern South America: results of Laurentia-Gondwana collision? Geology 20: 617-621.

Dalziel, I.W.D. 1997. Neoproterozoic-Paleozoic geography and tectonics: review, hypothesis, environmental speculation: Geological Society of América, Bulletin 109: 16-42.

Dalziel, I.W.D.; Dalla Salda, L.H.; Gahagan, L.M. 1994. Paleozoic Laurentia-Gondwana interaction and the origin of the Apalachian-Andean mountain system. Geological Society of America, Bulletin 106: 243-252.

Dalziel, I.W.D.; Cingolani, C.A.; Palmer, A.R. 1996. The Argentine Precordillera: A Laurentian Terrane? Penrose Conference Report, GSA Today (February): 1618.

Demicco, R.V. 1984. Wavy and lenticular-bedded carbonate ribbon rocks of the upper Cambrian Conococheague limestone, Central Apalachians. Journal of Sedimentary Petrology 53 (4): 1121-1132.

Demicco, R.V.; Hardie, L.A. 1994. Sedimentary structures and early diagenetic features of shallow marine carbonate deposits. Society for Sedimentary Geology (SEPM), Atlas Series 1: 265 p.

Duringer, P.; Vecsei, A. 1998. Middle Triasic shallow- water limestones from the Upper Muschelkalk of eastern France: the origin and depositional environment of some early Mesozoic fine-grained limestones. Sedimentary Geology 121: 57-70.

Drosser, M.L.; Bottjer, D.J. 1986. A semi-quantitative classification of ichnofabric. Journal of Sedimentary Petrology 56: 558-569.

Elrick, M.; Read, J.F. 1991. Cyclic ramp-to-basin deposits, Lower Mississippian, Wyoming and Montana: A combined field and computer modelling study. Journal of Sedimentary Petrology 61 (7): 1194-1224.

Flügel, E. 1982. Microfacies analysis of limestones, 633 p. Springer-Verlag, Berlin.

Ginsburg, R.N. 1971. Landward movement of carbonate mud: new model for regressive cycles in carbonates (abstract): American Association of Petroleum Geologists, Annual Meeting, Abstracts with programs 55: 340.

Goldhammer, R.K.; Dunn, P.A.; Hardie, L.A. 1990. Depositional cycles, composite sea level changes, cycle stacking patterns, and the hierarchy of stratigraphic forcing: examples from Alpine Trassic platform carbonates. Geological Society of America, Bulletin 102: 535-562.

Goldhammer, R.K.; Lehmann, P.J.; Dunn P.A. 1993. The origin of high-frequency platform carbonate cycles and third-order sequences (Lower Ordovician EI Paso Gp. West Texas): Constraints from outcrop data and stratigraphic modelling. Journal of Sedimentary Petrology 63 (3): 318-359.

Gómez, F.J.; Astini, R.A. 2001. Ichnofabric patterns in shallow marine carbonate tidal flats? of the Middle Cambrian in the Precordillera. In Reunión Argentina de Icnología, No. 4 y Reunión de Icnología del MERCOSUR, No. 2, Actas: p. 49. Tucumán.

Gómez, F.J.; Foglia, D.R.; Astini, R.A. 2002. Litofacies del perfíl tipo de la Formación La Laja y su transición con la Formación Zonda, Precordillera Oriental de San Juan. In Reunión Argentina de Sedimentología, No. 9, Actas: p. 25. Córdoba.

Gómez, F.J.; Foglia, R.D.; Astini, R.A. 2003. Renalcis in the Laurentian derived Middle Cambrian rocks of the Argentine Precordillera: Morphologies, distribution and stratigraphic position. In Congreso Latinoamericano de Sedimentología, No. 3, Actas: 209210. Belém, Brasil.

Gómez, F.J.; Astini, R.A. 2004. Rudstones intraclásticos inusuales en el Cámbrico de la Precordillera: Posible origen y significado paleoambiental. In Reunión Argentina de Sedimentología, Actas 1: 75-77. San Luis.

Gómez, F.J.; Astini, R.A. 2005. Cianobacterias renalciformes en el Cámbrico Medio de la Precordillera Argentina: morfología, posición estratigráfica y significado paleoambiental. Ameghiniana 42 (1): 221-232.

Gómez, F.J.; Ogle, Neil; Astini, R.A.; Kalin, R.M. 2005. Carbon and Oxygen isotope record of Early to Middle 
Cambrian carbonates (La Laja Formation) from the Precordillera terrane, Argentina. In Gondwana No. 12, Geological and Biological Heritage of Gondwana, Actas: 177 p. Mendoza, Argentina.

González Bonorino G.; González Bonorino, F. 1991. Precordillera de Cuyo y Cordillera Frontal en el Paleozoico temprano: terrenos bajo sospecha de ser autóctonos. Revista Geológica de Chile 18: 97-107.

Hardie, L.A. 1986. Stratigraphic models for carbonate tidal flat deposition. In Carbonate depositional environments, modern and ancient, Part 3: Tidal Flats (Hardie, L.A.; Shinn, E.A.; editors). Colorado School of Mines 81 (1): 59-74.

Harrington, H.J.; Leanza, A. 1943. Las Faunas del Cámbrico Medio de San Juan. Revista del Museo de La Plata 2 (11): 207-223.

Hinze, L.F.; Robinson, R.A. 1975. Middle Cambrian stratigraphy of the House, Wah Wah and adjacent ranges in western Utah. Geological Society of America Bulletin 86: 881-889.

Kayser, A. 1923. Fósiles primordiales e infrasilurianos de la República Argentina. Academia Nacional de Ciencias, No. 8 , Actas 1-2: 297-332.

Keller, M. 1999. Argentine Precordillera: Sedimentary and Plate tectonic History of a Laurentian Crustal Fragment in South America. Geological Society of America, Special Paper 431:131 p.

Keller, M.; Buggisch, W.; Bercowski, F. 1989. Facies and sedimentology of Upper Cambrian shallowing-upward cycles in the La Flecha Formation (Argentine Precordillera). Zentralblatt-fuer-Geologie-undPalaeontologie Teil 1 (5-6): 999-1011.

Keller, M.; Cañas, F.; Lenhert, O.; Vaccari, N.E. 1994. The Upper Cambrian and Lower Ordovician of the Precordillera (Western Argentina): some stratigraphic reconsiderations. Geological Society of London 31 (2): 115-132.

Keller, M.; Buggisch, W.; Lehnert, O. 1998. The stratigraphic record of the Argentine Precordillera and its plate tectonic background. In The protoAndean margin of Gondwana (Pankhurst, R.J.; Rapela, C.; editors). Geological Society of London, Special Publication 142: 35-56. London.

Kennard, J.M.; James, N.P. 1986. Thrombolites and stromatolites: two distinct types of microbial structures. Palaios 1: 492-503.

Kendall, C.G.St.C.; Schlager, W. 1981. Carbonates and relative changes in sea level. Marine Geology 44: 181-212.

Koerschner, W.F.; Read, J.F. 1989. Field and modeling studies of Cambrian carbonate cycles, Virginia Appalachians. Journal of Sedimentary Petrology 59: 654-687.

Kreisa, R.D. 1981. Storm-generated sedimentary structures in subtidal marine facies with examples from the Middle and Upper Ordovician of southwestern Virginia. Journal of Sedimentary Petrolology 51: 823-
848

Lehrmann, D.J.; Goldhammer, R.K. 1999. Secular variation in parasequence and facies stacking patterns of platform carbonates: A guide to application of stacking pattern analysis in strata of diverse ages and settings. In Advances in carbonate sequence stratigraphy: applications to reservoirs, outcrops and models (Harris, P.M.; et al.; editors). Society for Sedimentary Geology (SEMP), Special Publications 63: 187-225.

Logan, B.W.; Rezak, R.; Ginsburg, R.N. 1964. Classification and environmental significance of algal stromatolites. Journal of Geology 72 (1): 68-83.

Loske, W.P. 1993. La Precordillera del oeste argentine: Una cuenca de back arc en el Paleozoico. In Congreso Geológico Argentino No. 12 y Congreso de Exploración de Hidrocarburos No. 2, Actas 1: 5-13. Mendoza.

McKerrow, W.S.; Scotese, C.R.; Brasier, M.D. 1992. Early Cambrian continental reconstructions. Journal of the Geological Society of London 149: 559-606.

Mount, J.F. 1984. Mixing of siliciclastic and carbonate sediments in shallow shelf environments. Geology 12: 432-435.

Myrow, P.M. 1992. Pot and gutter casts from the Chapel Island Formation, southeast Newfoundland. Journal of Sedimentary Petrology 62: 999-1007.

Myrow, P.M. 1994. Pot and gutter casts from the Chapel Island Formation, southeast Newfoundland-Reply. Journal of Sedimentary Petrology A62: 708-709.

Odin, G.S.; Matter, A. 1981. De glauconiarum origine. Sedimentology 28: 611-641.

Ortiz, A.; Zambrano, J.J. 1981. La provincia geológica de la Precordillera Oriental. In Congreso Geológico Argentino No. 8, Actas 3: 59-74. San Luis.

Osleger, D. 1991. Subtidal carbonate cycles: Implications for allocyclic versus autocyclic controls. Geology 19: 917-920.

Osleger, D.; Read, J.F. 1991. Relation of eustasy to stacking patterns of meter-scale carbonate cycles, Late Cambrian, U.S.A. In Orbital forcing and sedimentary sequences (Fischer, A.G.; editor). Journal of Sedimentary Petrology 61 (7): 1225-1252.

Osleger, D.; Read, J.F. 1993. Comparative analysis of methods used to define eustatic variations in outcrop: Late Cambrian interbasinal sequence development. American Journal of Science 293: 157-216.

Palmer, A.R. 1971. The Cambrian of the Appalachianand the eastern New England regions, eastern United States. In Cambrian of the New World (Holland, C.H.; editor). Wiley-Interscience: 289-332, London.

Palmer, A.R.; Halley, R. 1979. Physical stratigraphy and trilobite biostratigraphy of the Carrara Formation (Lower and Middle Cambrian) in the southern Great Basin. U.S. Geological Survey, Professional Paper 1047: 1-130.

Peryt, T.M. 1983. Oncoids: comment to recent developments. In Coated Grains (Peryt, T.M.; editor). Springer-Verlag: $634 \mathrm{p}$. 
Poulsen, V. 1958. Contributions to the Middle Cambrian paleontology and stratigraphy of Argentine. Matematisk-fisiske Meddelelser, Danske Videnskabernes Selsk 31 (8): 1-23.

Pratt, B.R.; James, N.P. 1986. The St. George Group (Lower Ordovician) of western Newfoundland: tidal flat island model for carbonate sedimentation in shallow epeiric seas. Sedimentology 33: 313-343.

Radwánski, A.; Szulczewski, M. 1966. Jurassic stromatolites of the Villany Mountains (Southern Hungary). Annales Universitatis Scientiarum Budapestinensis Rolando Eötvös Sectio Geologica 9: 87107.

Reineck, H.E.; Singh, I.B. 1980. Depositional sedimentary environments. Springer-Verlag: 549 p. Berlin Heidelberg, New York.

Ramos, V.A. 2004. Cuyania, an exotic block to Gondwana: review of a historical success and the present problems. Gondwana Research 7 (4): 1009-1026.

Rankey, E.C.; Walker, K.; Srinivasan, K. 1994. Gradual establishment of lapetan 'passive' margin sedimentation: stratigrafic consequences of Cambrian episodic tectonism and eustasy, southern Appalachians. Journal of Sedimentary Research B64 (3): 298-310.

Rapalini, A.E.; Astini, R.A. 1998. Paleomagnetic confirmation of the Laurentian origin of the Argentine Precordillera. Earth and Planetary Science Letters 155: $1-14$.

Rolleri, E.O. 1969. Rasgos tectónicos generales del valle de Matagusanos y de la zona entre San Juan y Jocolí, Provincia de San Juan, República Argentina. Revista de la Asociación Geológica Argentina 24 (4): 408412.

Schlager, W. 1989. Drowning unconformities on carbonate platforms. In Controls on carbonate platform and basin development (Crevello, P.D.; Wilson, J.L.; Sarg, J.F.; Read, J.F.; editors). Society of Economic Paleontologists and Mineralogists (SEPM), Special Publication 44:15-25.

Shinn, E.A. 1983. Tidal flat environment. In Carbonate depositional environments (Scholle, P.A.; Bebout, D.G.; Moore, C.H.; editors). American Association of Petroleum Geologists, Memoir 33: 708 p.

Sial, A.N.; Ferreira, V.P.; Toselli, A.J.; Aceñolaza, F.G.; Pimentel, M.M.; Parada, M.A.; Alonso, R.N. 2001. C and $\mathrm{Sr}$ isotopic evolution of carbonate sequences in NW Argentina: implications for a probable Precambrian-Cambrian transition. Carbonates and Evaporites 16 (2): 141-152.

Spencer, R.J.; Demicco, R.V. 1989. Computer models of carbonate platform cycles driven by subsidence and eustasy. Geology 17: 165-168.

Spencer, R.J.; Demicco, R.V. 2002. Facies and sequence stratigraphy of two Cambrian Grand Cycles: Implications for Cambrian sea level and origen of Grand Cycles. Bulletin of the Canadian Petroleum Geology 50 (4): 478-491.
Srinivasan, K.; Walker, K. 1993. Sequence stratigraphy of an intrashelf basin carbonate ramp to rimmed platform transition: Maryville Limestone (Middle Cambrian), southern Appalachians. Geological Society of America, Bulletin 105: 883-896.

Stelzner, A. 1923-1924. Contribuciones a la geología de la República Argentina. Actas Academia Nacional de Ciencias (1-2): 228 p. Córdoba.

Thomas, W.A.; Astini, R.A. 1999. Simple-shear conjugate rift margins of the Argentine Precordillera and the Ouachita embayment of Laurentia. Geological Society of America, Bulletin 111 (7): 1069-1079.

Thomas, W.A.; Astini, R.A.; Mueller, P.A.; Gehrels, G.E.; Wooden, J.L. 2004. Transfer of the Argentine Precordillera terrane from Laurentia: constraints from detrital-zircon geochronology. Geology 32 (11): 965968.

Tucker, M.E. 1982. Storm-surge sandstones and the deposition of interbedded limestone: Late Precambrian, southern Norway. In Cyclic and event stratification (Einsele, G.; Seilacher, A.; editors). Springer-Verlag: 363-370. Berlin.

Tucker, M.E.; V.P. Wright 1990. Carbonate Sedimentology. Blackwell Science: 482 p. Oxford.

Vaccari, N.E. 1994. Las faunas de trilobites de las sucesiones carbonáticas del Cámbrico y Ordovícico temprano de la Precordillera septentrional, República Argentina. Tesis Doctoral (Unpublished), Universidad Nacional de Córdoba: 271 p. Córdoba.

Vail, P.R.; Mitchum, R.M. Jr.; Thompson, S. 1977. Seismic stratigraphy and global changes of sea level, No. 3: relative changes of sea level from coastal onlap. In Seismic stratigraphy-Applications to hydrocarbon exploration (Payton, C.E.; editor). American Association of Petroleum Geologists, Memoir 26: 63-81.

Vail, P.R.; Audemard, F.; Bowman, S.A.; Eisner, P.N.; Pérez Cruz, C. 1991. The stratigraphic signatures of tectonics, eustasy and sedimentology-an overview. In Cycles and events in stratigraphy (Einsele, G.; Ricken, W.; Seilacher, A.; editors). Springer-Verlag: 617-659.

Wilkinson, B.H.; Diedrich, N.W.; Drummond, C.N. 1996. Facies successions in peritidal carbonate sequences. Journal of Sedimentary Research 66: 1065-1078.

Wilkinson, B.H.; Diedrich, N.W.; Rothman, E.D.; Drummond, C.N. 1997. Stratal order in peritidal carbonate sequences. Journal of Sedimentary Research 67: 1068-1082.

Wilkinson, B.H.; Diedrich, N.W.; Drummond, C.N.; Rothman, E.D. 1999. Poisson processes of carbonate accumulation on Paleozoic and Holocene platforms. Journal of Sedimentary Research 69: 338-350.

Wilson, J.L.; Jordan, C. 1983. Middle shelf environment. In Carbonate depositional environments (Scholle, P.A.; Bebout, D.G.; Moore, C.H.; editors). American Association of Petroleum Geologists, Memoir 33: 297-343. 